\title{
Viewpoints
}

\section{Linking Social Cognition to Learning and Memory}

\author{
Heloise Leblanc ${ }^{1,2}$ and Steve Ramirez ${ }^{1,3,4,5}$ \\ ${ }^{1}$ Department of Psychological and Brain Sciences, Boston University, Boston, Massachusetts, 02119, ${ }^{2}$ Boston University School of Medicine, Boston, \\ Massachusetts, 02118, ${ }^{3}$ Department of Biomedical Engineering, Boston University, Boston, Massachusetts, 02119, ${ }^{4}$ Neurophotonics Center at \\ Boston University, Boston, Massachusetts, 02119, and ${ }^{5}$ Center for Systems Neuroscience at Boston University, Boston, Massachusetts, 02119
}

Many mammals have evolved to be social creatures. In humans, the ability to learn from others' experiences is essential to survival; and from an early age, individuals are surrounded by a social environment that helps them develop a variety of skills, such as walking, talking, and avoiding danger. Similarly, in rodents, behaviors, such as food preference, exploration of novel contexts, and social approach, can be learned through social interaction. Social encounters facilitate new learning and help modify preexisting memories throughout the lifespan of an organism. Moreover, social encounters can help buffer stress or the effects of negative memories, as well as extinguish maladaptive behaviors. Given the importance of such interactions, there has been increasing work studying social learning and applying its concepts in a wide range of fields, including psychotherapy and medical sociology. The process of social learning, including its neural and behavioral mechanisms, has also been a rapidly growing field of interest in neuroscience. However, the term "social learning" has been loosely applied to a variety of psychological phenomena, often without clear definition or delineations. Therefore, this review gives a definition for specific aspects of social learning, provides an overview of previous work at the circuit, systems, and behavioral levels, and finally, introduces new findings on the social modulation of learning. We contextualize such social processes in the brain both through the role of the hippocampus and its capacity to process "social engrams" as well as through the brainwide realization of social experiences. With the integration of new technologies, such as optogenetics, chemogenetics, and calcium imaging, manipulating social engrams will likely offer a novel therapeutic target to enhance the positive buffering effects of social experiences or to inhibit fear-inducing social stimuli in models of anxiety and post-traumatic stress disorder.

Key words: behavior; engram; learning; memory; optogenetics; social

\section{Introduction}

Social learning involves at least two agents, at least one of which updates their knowledge base by acquiring information from the other (for details, see Box 1). Classifications of social learning and cognition are wide-ranging and divisive, often dependent on the specialty of the researchers defining the behaviors and their opinions regarding the presence of higher-order animal cognition in nonhuman species (Zentall and Galef, 1988; Choleris and Kavaliers, 1999; Lacey and Solomon, 2003; Zentall, 2006; Olsson and Phelps, 2007; Wolff, 2007; Christov-Moore et al., 2014; Gariépy et al., 2014; Keum and Shin, 2016, 2019; Debiec and Olsson, 2017; Kiyokawa and Hennessy, 2018; Morozov, 2018; Sivaselvachandran et al., 2018; Carcea and Froemke, 2019). How social learning in rodents can be classified per se is outside the focus of this review and is further discussed elsewhere (Zentall

\footnotetext{
Received May 22, 2020; revised Sep. 30, 2020; accepted Oct. 2, 2020.

Author contributions: H.L. and S.R. wrote the paper. H.L. and S.R. edited and commented on the manuscript.

This work was supported by National Institutes of Health Early Independence Award DP5 0D023106-01, Transformative R01, Brain and Behavior Research Foundation Young Investigator Grant, Society of Fellows at Harvard University Milton Grant, Ludwig Family Foundation Grant, and McKnight Foundation Memory and Cognitive Disorders Award. We thank Abby Finkelstein for exceptional mentorship, extensive comments and help with editing the manuscript, and intellectual feedback on all stages of manuscript preparation.

The authors declare no competing financial interests.

Correspondence should be addressed to Steve Ramirez at dvsteve@bu.edu.

https://doi.org/10.1523/JNEUROSCI.1280-20.2020

Copyright @ 2020 The authors
}

and Galef, 1988; Zentall, 2006). In this review, we begin with the notion of a "social engram" and propose the concept as a unifying theme across studies seeking to understand the physical basis of complex cognition and behavior. In particular, we focus on recent research that illuminates the critical role of the hippocampus in social cognition in rodents and humans, especially with regard to areas, such as CA2, which plays a critical role in connecting social behaviors and general mnemonic outputs. In the next section, we overview social learning and acquisition of memory and discuss the social modulation of instrumental and skilled actions, spatial tasks, and food preference. Through the lens of these types of social learning, we highlight how factors, such as the sex of a learner or familiarity of a conspecific, can directly affect learning curves. We then examine how these factors relate to the fact that many pathways necessary and sufficient for social cognition coincide with general learning pathways. Finally, we transition to the social modulation of learning and memory, and how social stimuli, especially those of familiar individuals, can suppress or enhance a variety of fear responses in rodents. By deconstructing social learning's neural and behavioral mechanisms, we may develop novel strategies that further leverage social influences as putative therapeutic interventions.

\section{The Hippocampus and the Social Engram}

The term "engram," the enduring structural and functional manifestation of a memory, was coined $>100$ years ago (Schacter et 
al., 1978; Josselyn and Tonegawa, 2020). Recently, the engram literature has experienced a resurgence in light of new imaging and molecular techniques that view and manipulate neural ensembles involved in contextual and emotional memory with unprecedented spatial-temporal resolution. In rodent models, for over a decade, a rich body of work has focused specifically on the formation and retrieval of fear engrams (S. Ramirez et al., 2015; Denny et al., 2017; Josselyn and Tonegawa, 2020). The behavioral manifestations of fear in rodents can be quantified through a battery of outputs, including freezing, which offers a robust behavioral readout that can also be manipulated and studied at the cellular level. In response to such groundbreaking advances, more researchers have begun to investigate complex, multimodal behaviors, such as sociality. The co-occurrence of fear and social behaviors has become of particular interest as it has implications for many psychiatric disorders, including social anxiety, phobias, and post-traumatic stress disorder (PTSD) (Storm and Tecott, 2005; Charuvastra and Cloitre, 2008; Flinn et al., 2011).

Box 1. Social learning was defined by Conte and Paolucci (2001) as a "phenomenon by means of which a given agent (the learning agent) updates its own knowledge base (adding to, or removing from it a given information, or modifying an existing representation) by perceiving the positive or negative effects of any given event undergone or actively produced by another agent on a state of the world which the learning agent has as a goal." Specifically, there exist at least two types of social learning: facilitation and imitation. Facilitation involves observing the features and behaviors of a social conspecific and its environment to acquire novel information that can be used to update an observer's knowledge base. In social facilitation, the social conspecific merely acts as an implicit source or indicator about the shared environment while maintaining increased valence compared with nonsocial stimuli because of the evolutionary significance placed on social stimuli. This type of social learning is known to be present in various social species, including rodents, birds, primates, etc. In imitation, the observer has a mental representation of the conspecific as a suitable model, and therefore mimics the model to learn behaviors or knowledge that can achieve their goals. This is as a more deliberate type of social learning dependent on the observer's beliefs about the model and is thought to require higher-order social cognition only found in nonhuman and human primates (Conte and Paolucci, 2001; Olsson and Phelps, 2007). However, recent work has shed light on various additional species, including rodents, which we believe have highly organized and dedicated neural circuitry for processing and extracting information from complex social behaviors.

A recent study used activity-dependent cellular tagging and in vivo calcium imaging strategies to identify cells processing a social engram in the ventral CA1 hippocampal subregion (Okuyama et al., 2016). This finding opened the possibility of imaging, perturbing, and cataloguing cells dedicated to processing discrete social experiences. The researchers found an ensemble of neurons that were preferentially reactivated in the presence of a previously encountered conspecific compared with an unfamiliar conspecific. In addition, they found that, although these neural ensembles projected to the nucleus accumbens shell, olfactory bulb, and basolateral amygdala, only the projection to the nucleus accumbens was necessary for social discrimination. New discoveries about the social engram ensued, and suggested a pathway for social recognition memory involving the olfactory system (Matochik, 1988; Kiyokawa et al., 2012), dorsal CA2 (Dudek et al., 2016; Mitre et al., 2016; A. S. Smith et al., 2016; Meira et al., 2018), ventral CA1 (Dudek et al., 2016; Mitre et al., 2016; A. S. Smith et al., 2016; Meira et al., 2018), and nucleus accumbens (Okuyama et al., 2016; Okuyama, 2018), as well as modulatory roles for the mPFC (Tanimizu et al., 2017; Gutzeit et al., 2020), ACC (Tanimizu et al., 2017), amygdala (Tanimizu et al., 2017; Fernández et al., 2018), lateral septum (Fernández et al., 2018), and hypothalamus (Dudek et al., 2016; Mitre et al., 2016; A. S. Smith et al., 2016).

\section{CA2: the black box of the hippocampus}

The central role of the hippocampus in learning and memory was historically centered around the influential concept of a "trisynaptic pathway" defined by three main subregions: CA1, CA3, and the dentate gyrus (CA4/DG) (Teyler and Discenna, 1984; Langston et al., 2010; Dudek et al., 2016; Tzakis and Holahan, 2019). Through lesions, electrophysiology, calcium imaging, and optogenetic studies, the roles of these subregions were often rigidly defined: CA1 was proposed to specialize in processing the spatiotemporal components of memory, CA3's functions included pattern completion and rapid, one-trial encoding, and the DG's functions involved pattern separation and orthogonalizing inputs to discrete populations of cells (Teyler and Discenna, 1984; Kesner et al., 2004; Langston et al., 2010). Although defined as early as 1934 by Rafael Lorente de Nó, CA2 was frequently referred to together with CA3a and remained largely understudied because of difficulty in identifying genetic, cell type, or otherwise topographical borders with CA3, as well as its obscure functions in the synaptic circuits of the hippocampus. Most work examining memory and its neural circuits would refer to the Schaffer collateral pathway, from the entorhinal cortex layer II through the hippocampus: DG-CA3-CA1-subiculum (Langston et al., 2010), or the direct pathway from entorhinal cortex layer III directly to CA1 (Kajiwara et al., 2008; Langston et al., 2010; Maccaferri, 2011), often leaving out the role of CA2 in the pathway (Tzakis and Holahan, 2019).

As the field gained new technological methods for determining brain structure and function, however, the multifaceted functions of the hippocampus, including its role in facilitating food preference and social memory, became even more apparent (Okuyama et al., 2016; Chiang et al., 2018; Okuyama, 2018). New molecular markers also made identifying and defining CA2 much more tractable (DeVito et al., 2009; Dudek et al., 2016; Meira et al., 2018), allowing scientists to delve into its neuromodulatory influences and its contribution to social modes of learning and memory (Dudek et al., 2016; Meira et al., 2018; Okuyama, 2018; Fernandez-Lamo et al., 2019; Modi and Sahin, 2019; Tzakis and Holahan, 2019; Oliva et al., 2020). Recent physiological work suggests that sharp-wave ripples (SWRs) occurring in dorsal CA2 during sleep play a key role in the formation of the social engram, as these SWRs propagate to vCA1 to consolidate novel social experience with a conspecific (Oliva et al., 2020) (Fig. 1). Interestingly, Oliva et al. (2020) suggested that SWRs from dorsal CA2 to CA1 during social memory consolidation act similarly to SWRs from CA3 to CA1 during spatial memory consolidation (Dragoi and Tonegawa, 2013), a type of memory the hippocampus is traditionally viewed to encode (Teyler and Discenna, 1984; Langston et al., 2010). The ventral horn of CA2 is even more understudied than dorsal CA2, despite its putative 
role in learning and memory and its modulation of social memory and behavior (Benoy et al., 2018). Intriguingly, ventral CA2 has a dense population of estrogen receptors that could play a role in sexual dimorphism associated with social behaviors and psychiatric disorders (Shughrue and Merchenthaler, 2000; Chevaleyre and Piskorowski, 2016), although much work remains to test for structural and functional differences along CA2's DV axis. Overall, there is great potential for future research to reveal the real-time and elaborate roles that these hippocampal regions play in social cognition and behavior.

\section{Social Learning and Acquisition of Memory}

Social learning of skills and actions

From an early age, humans and other mammals learn how to survive in the world by observing those around them. Indeed, research suggests that humans have evolved to acquire new skills more efficiently through social imitation than by individual trial and error. A classic example of social learning in humans is the Bandura Bobo doll experiment, in which toddlers imitate previously observed aggressive behavior of an adult toward a doll (Bandura et al., 1961). Such socially acquired behaviors are seen in both humans and rodents. For example, roof rats can learn how to extract and eat seeds from pine cones simply by watching conspecifics performing the behavior (Wolff, 2007). Additionally, rodents' learning in instrumental operational tasks is facilitated by observation of conspecifics. Rats learn instrumental tasks, such as pressing levers or bars for rewards, much more rapidly from observation of conspecifics performing the same tasks than by individual training (Zentall and Levine, 1972). Conversely, if the conspecific is not actively performing the task but is simply placed in the same area as an observer rodent, then the latter's learning is impaired, suggesting that the actual observation of action is necessary to facilitate learning, rather than social presence per se.

Of note, a separate study compared strain-dependent effects on social instrumental learning and found that observation of conspecifics of a different strain improved performance significantly more than observation of same-strain conspecifics (Saggerson and Honey, 2006). Although the authors manipulated strain instead of familiarity per se (all subjects were novel to one another), they raise the possibility that demonstrator-observer pairs of the same strain would deem each other more "familiar" than pairs of a different strain because animals of the same strain would be more similar to the cage mates with which the subjects had been reared. While not explicitly studied as of yet, we propose that a similar learning dissociation would occur with a nonfamiliar and familiar conspecific: that is, same-strain conspecifics with no prior interaction with the observer would learn more efficiently than samestrain conspecifics with such prior interaction. A potential psychological mechanism for this effect may lie in the interaction of instrumental learning with social memory. Theoretically, during an encounter with a familiar conspecific, the social memory engram is activated to produce retrieval of this familiar social encounter (Okuyama, 2018). Because social events are often favorable to a species' survival, the brain responds by sending reward signals before the conspecific even starts the task (Robinson et al., 2002; Modi and Sahin, 2019), essentially satiating a drive for reward. Consequently, when the conspecific performs an action (e.g., pressing a lever) and gets a result (e.g., a reward), there is less value and attention placed on the action and its result. Although there is an overall facilitation of learning, the Pavlovian positive association of the familiar conspecific may compete with the operant conditioning task. This type of interaction has been demonstrated to happen in rodents and humans (Kohn, 1976; Torregrossa and Taylor, 2013; Mkrtchian et al., 2017; Ferbinteanu, 2019). On the other hand, a nonfamiliar conspecific does not elicit social memory retrieval; rather, it can be argued that a social memory is being formed (Okuyama et al., 2016; Okuyama, 2018). Therefore, when the conspecific presses the lever and gets a reward, the salience of both a social and a material reward synergizes, creating a stronger association and consequently faster learning of the task. The Pavlovian positive association of the social encounter enhances the formation of the operant task memory. However, both familiar and unfamiliar conspecific interactions may facilitate learning of instrumental tasks relative to individual learning through "local enhancement" (Conte and Paolucci, 2001): the observation of a conspecific leads to increased attention to the location of the lever and the possibility of a reward compared with during classical operant tasks, in which the discovery of this action-result pairing occurs accidentally. 


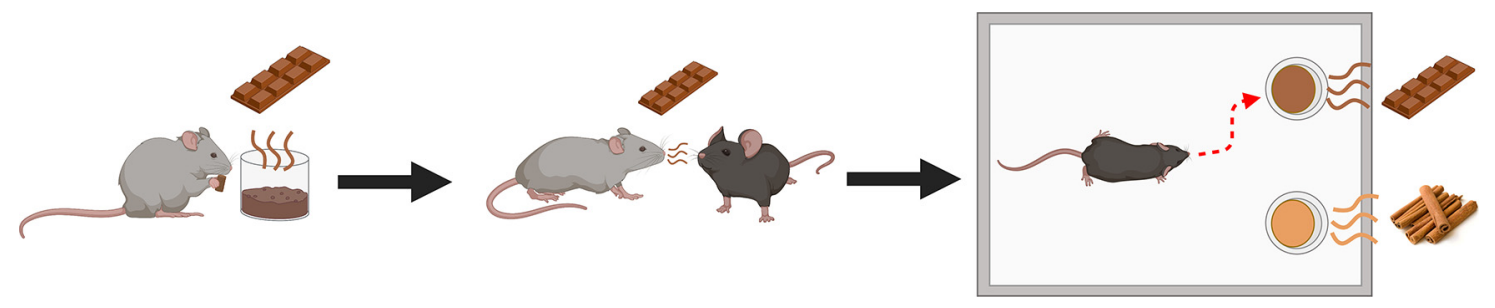

Figure 2. STFP. A rodent ("demonstrator") is exposed to a flavored food and allowed to eat it for a specified period of time. Next, the demonstrator is removed and placed near a conspecific ("observer"). The scent of the food and the chemical carbon disulfide $\left(\mathrm{CS}_{2}\right)$, a volatile from the demonstrator's breath, are detected by the "observer" during the social interaction. This single exposure leads the observer to prefer the scent and flavor associated with the demonstrator over a novel flavor when given the choice at a later time. This preference can last up to weeks in the observer rodents.

\section{Social mapping and learning in space}

The hippocampus constructs relational networks that link events and episodes while providing flexible representations across spatial dimensions (O’Keefe and Nadel, 1978; Eichenbaum, 2004; Buzsáki and Moser, 2013). This ability to receive sensory input and integrate information in a way that allows an animal to navigate regularities in their environment is critical for survival. Space, however, can be defined more abstractly than in the physical sense, and hippocampus cells have been shown to multiplex numerous streams of information that are not tied to physical $x, y$, $z$ coordinates. For instance, hippocampal cells are modulated by both time and reward (Buzsáki and Moser, 2013; Eichenbaum, 2014; Schafer and Schiller, 2018) and are activated by a broad range of abstract relations within an event or episode. In addition, for social creatures, a major factor to be considered in space and over time is the social interactions between different individuals (Maren et al., 2013). This "social space" encompasses not only social stimuli in physical space, but also constructs of social "power" and "affiliation" (Schiller et al., 2015). Hierarchical structures or bonds of kinship in complex social networks can be construed as cognitive maps, which are also believed to be represented by the hippocampus (Eichenbaum, 2015; Montagrin et al., 2018).

The intersection of space and social stimuli in the hippocampus makes it an ideal region for mediating observational learning in spatial tasks (Conte and Paolucci, 2001). Many researchers have investigated this effect in maze tasks and have consistently found that the acquisition of spatial maps and task-solving strategies is improved with a demonstrating conspecific present (Petrosini et al., 1996; Mou and Ji, 2016; Takano et al., 2017; Danjo et al., 2018). Recently, studies have revealed that this improvement involves CA1 and CA2 of the hippocampus (Mou and Ji, 2016; Danjo et al., 2018; Oliva et al., 2020). One study found that, if a rat runs in place while watching a demonstrator perform a spatial task, the observer will acquire a sequence of neuron firing that is reactivated preferentially when it does the spatial task itself (Mou and Ji, 2016). More specifically, CA1 place cells can be tuned to specific spatial locations, without experience of the spatial layout itself, through social observation. For instance, CA1 place cells can represent the "self" or "other," or both concurrently, in a T-maze task (Danjo et al., 2018). When an animal observes a spatial task, all of these cells might evaluate the environment synergistically and encode the spatial information necessary for subsequent success by the observer. Another study discovered similar social cells in CA2: the cells fired more in the location with the conspecific than in the location in space itself (Oliva et al., 2020). This intimate overlap of hippocampal neural circuits in social and spatial memory suggests a putative adaptation in social animals and is a crucial topic of future study for understanding social cognition and learning.
A myriad of studies support the notion that social experiences leave a distributed imprint in the brain beyond the hippocampus. For instance, the cerebellum, an area known to play a part in spatial (Darmohray et al., 2019; Dziura and Thompson, 2019; Leggio et al., 2000) and social memory (D'Mello and Stoodley, 2015; Sokolov, 2018; Dziura and Thompson, 2019), functions within a larger cortico-hippocampal network. Indeed, Leggio et al. (2000) demonstrated the necessity of the cerebellum for spatial memory acquisition through observation. Yet much work remains to be done to better understand this complex phenomenon. With a better understanding of how all circuits associated with social learning influence and communicate with each other, we may be able to develop more targeted therapeutic approaches in psychiatric disorders with social deficits. Promising leads include, for example, the observation of cerebellar dysfunction in autism spectrum disorder (D'Mello and Stoodley, 2015), a disorder most commonly known for its impaired social cognition and communication. How cerebellar function affects social cognition and spatial awareness, and how it interfaces with other social circuits in the brain affected by ASD is still relatively unknown. With a better understanding of cerebellar function, we will be able to develop novel targets to ameliorate specific deficits seen in ASD and similar psychiatric disorders.

\section{Social transmission of food preference}

Social transmission of food preference (STFP) is one of the most studied forms of social learning in rodent models. STFP (Fig. 2) involves a "demonstrator" rodent first eating a flavored food and then being placed in a new cage to interact with an "observer." Immediately or $24 \mathrm{~h}$ afterward, when the observer is given two choices of food flavor, the observer prefers to eat the food that the demonstrator was exposed to the day before (Galef and Wigmore, 1983). This "transfer" of preference is known to involve olfactory cues, composed of the food odor and carbon disulfide, emitted in the demonstrator's breath during the social encounter (Galef et al., 1988). Importantly, this transfer can only occur between a live conspecific's breath and the observer (Galef and Stein, 1985), emphasizing the social nature of this type of learning. Research has suggested many brain regions potentially associated with this phenomenon, including the hippocampus, basolateral amygdala, orbitofrontal cortex, and basal forebrain structures (Bunsey and Eichenbaum, 1995; Vale-Martínez et al., 2002; Ross et al., 2005; Wang et al., 2006; C. A. Smith et al., 2007; Carballo-Márquez et al., 2009). However, like many other social phenomena, various reports suggest different brain regions are necessary or sufficient for STFP. For instance, early work demonstrated that neurotoxic lesions of the hippocampus left immediate retrieval of preference intact but produced significant 

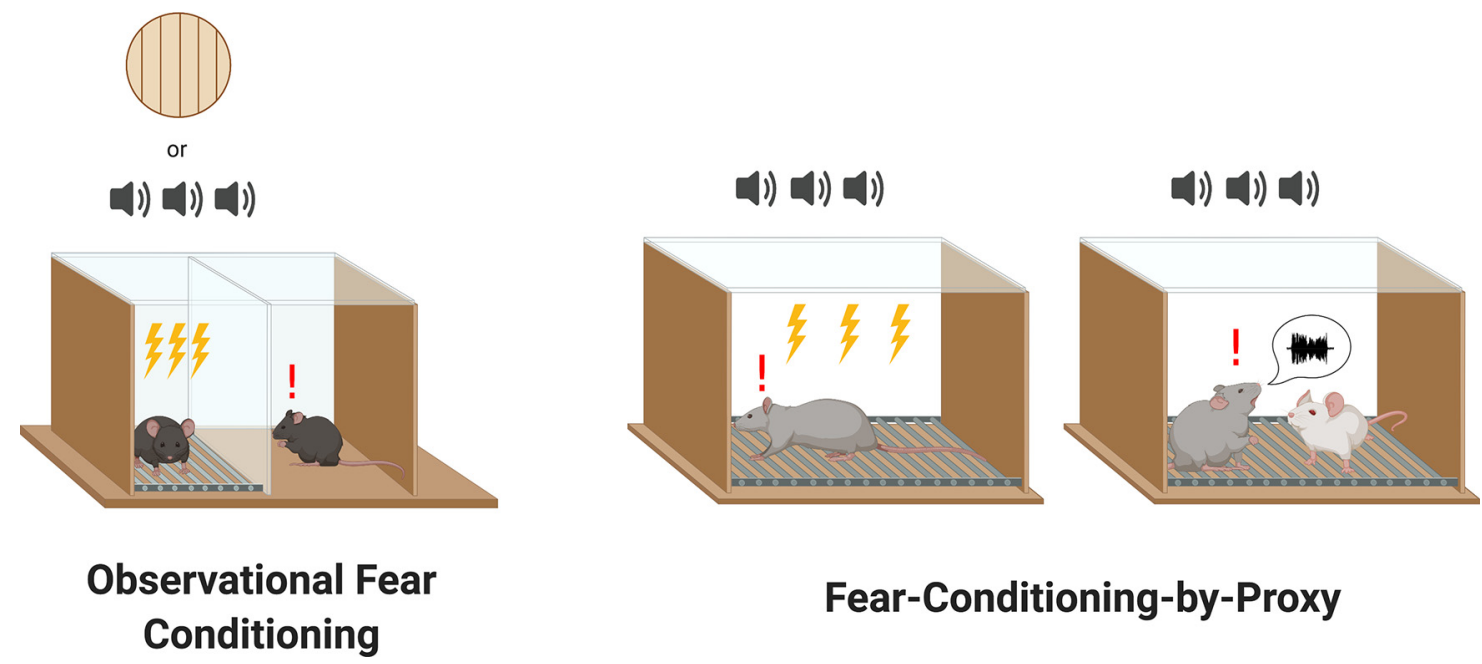

\section{Fear-Conditioning-by-Proxy}

Figure 3. Social fear learning paradigms. The two primary paradigms used to study social fear learning in rodents are observational fear conditioning and fear conditioning by proxy. Observational fear conditioning consists of a rodent (mouse or rat) observing a demonstrator conspecific receiving shocks (left). This paradigm elicits relatively robust learning in observer rodents whether the shock is paired with auditory stimuli or with context alone (represented by a yellow circle with stripes). In fear conditioning by proxy, a demonstrator rat undergoes auditory fear conditioning when alone (right). The following day, an observer rat is placed with the demonstrator conspecific, which is presented with tones from the previous fear-conditioning session without delivery of unconditioned stimuli. The fearful response of the demonstrator can elicit fear learning in the observer that is detectable the next day during a recall session.

deficits in the long-term $(24 \mathrm{~h})$ retention of this preference (Winocur, 1990; Bunsey and Eichenbaum, 1995; Winocur et al., 2001). Conflicting results soon followed, when Burton et al. (2000) demonstrated that the hippocampus was not necessary for $24 \mathrm{~h}$ retention. Burton et al. (2000) also lesioned the basolateral amygdala, a region closely associated with the hippocampus in memory, and again found no deficits in STFP. Still other studies revealed that hippocampal damage induced retrograde amnesia in STFP, suggesting a role for hippocampus in at least parts of this phenomenon. Following similar patterns of studies on systems consolidation of memory, a consensus emerged that the hippocampus was necessary for the retrieval of recent STFP memories, whereas remote memory is more dependent on the neocortex (Winocur and Moscovitch, 1999; Countryman et al., 2005; Countryman and Gold, 2007; C. A. Smith et al., 2007; Carballo-Márquez et al., 2009; Monfils and Agee, 2019). However, this is still debated, as subsequent studies with NMDA- and TTX-induced lesions of the hippocampus also demonstrated no recent memory deficits in STFP (Thapa et al., 2014).

An important factor to consider is the satiety of the animals during different aspects of the STFP paradigm. Most of the previously mentioned studies deprived the animals of food before the social interaction and retention tests, making the animals more motivated to consume the food placed in front of them during the tests. However, few studies have tried to examine the effects of satiety in this paradigm, especially as it relates to the hippocampus. One study (Agee and Monfils, 2018) deprived observers of food up until the social interaction with the demonstrator but then provided food ad libitum before preference testing. The authors reasoned that this would increase how "picky" the subjects would be, enhancing small differences in preference that may be hidden in hungry animals. Even with a decreased appetite, the observers still showed a significant preference for the demonstrated food in the tests. A separate study (Burton et al., 2000) repeated their hippocampal lesion experiment with animals fed ad libitum throughout the entire paradigm. They found that, as expected, observers in general ate less during the testing sessions because of increased satiety compared with their experiment with food-deprived animals. Interestingly, however, satiated animals with hippocampal lesions ate a greater proportion of the "demonstrated food" compared with controls, without eating more food total. These nuances indeed could be an indication of the hippocampus' relatively understudied but active role in STFP.

The hippocampus has substantial influence in the regulation of appetitive behaviors. In particular, the ventral hippocampus contains receptors for hormones associated with food intake, including ghrelin (Carlini et al., 2004; Grillo et al., 2009; Hsu et al., 2015, 2018a), leptin (Dhar et al., 2014), insulin (Calvo-Ochoa and Hernández-Ortega, 2014), and glucagon (Hsu et al., 2018b). In addition, the hippocampus has been closely linked to the vagus-dependent gut-brain connection, having indirect communication with the hindbrain medial nucleus tractus solitarius, which integrates gastrointestinal signaling information for the brain (Castle et al., 2005; Biggio et al., 2009; Suarez et al., 2019). The necessity of the hippocampus in nonsocial appetitive behaviors has been investigated through lesions as well, with varying conclusions about its necessity depending on the type of lesion, level of satiety of the subjects, and paradigm used (Jarrard, 1973; Davidson and Jarrard, 1993; Schmelzeis and Mittleman, 1996; Clifton et al., 1998; Flaherty et al., 1998; Tracy et al., 2001). Of particular interest is that the hippocampus has special roles in anticipation of food and meals (linking specific stimuli to predicted meals), as well as the regulation of food motivation based on energy state (Tracy et al., 2001). For STFP, it may be that the hippocampus plays different roles depending on the level of food access and satiety of the subjects, as well as the type of food deprivation: limited time for food access (meals) or limited amount of food given per day (all day access). More research is needed to elucidate how the hippocampus is involved in STFP and the potential role of satiety and hunger in this social transfer of information.

\section{Social learning with negative experiences: the study of fear} and its transmission

An extensively studied topic in both humans and rodents is the social transmission of fear. In humans, many studies have traced phobias to social roots, such as parental anxiety and affective responses. Subclinical fears can also be acquired by observation, 
as was demonstrated by two early behavioral studies (Hornik et al., 1987; Gerull and Rapee, 2002). In both experiments, a toddler was shown an object (stimulus), along with the child's mother's facial response to the stimulus (positive or negative). Hornik et al. (1987) showed that toddlers acquired more avoidance and fearful behavior toward an object paired with a mother's negative response compared with an object paired with a mother's positive response (Hornik et al., 1987). Gerull and Rapee (2002) additionally demonstrated that the fear behavior persisted even after the mother no longer had a negative affect toward an object, suggesting not only effects on direct avoidance behavior, but also the lasting association of a stimulus to a threat via social transmission. In greater severity, the development of PTSD is highly linked to the social nature of the trauma. Specifically, there is an increased probability of developing PTSD from an interpersonal encounter or event of "human design" than from other external stimuli (Charuvastra and Cloitre, 2008). This suggests that humans appropriate a disproportionate amount of weight to social encounters for learning and memory, especially for threatening stimuli.

\section{Rodent models for indirect fear acquisition: two species, multiple paradigms, and little consensus}

Rodents seem to have a predisposition for fear learning from social stimuli. Several forms of such learning have been observed. One can distinguish, for example, observational fear conditioning and fear conditioning by proxy (Fig. 3). Observational fear conditioning results from a direct observation of a conspecific receiving an aversive stimulus (e.g., shock), and therefore involves the observer learning to associate and ego-centrically process the conspecific's aversive experience within a specific context (Jeon et al., 2010; Morozov and Ito, 2018). Fear conditioning by proxy, often grouped with observational fear conditioning, is a form of socially mediated fear learning in which a nonconditioned rodent acquires a fear memory by observing the response of a conspecific to a cue or context it was previously conditioned to fear (Debiec and Olsson, 2017). Unlike observational fear conditioning where the 2 rodents are restricted from contact, the transmission of fear conditioning by proxy requires interactions between freely moving animals during the experience. After the interaction, the observer rodent shows increased freezing during subsequent exposure to the cue or context (Bruchey et al., 2010; E. J. Kim et al., 2010; Jones et al., 2014). Freezing, although used by many as an indicator of fear in rodents, can also be supplemented by other indicators including autonomic responses, such as pupil dilation and hypothalamicpituitary-adrenal (HPA) axis activation (Kiyokawa et al., 2007); defecation; or other behaviors, such as darting, rearing, and grooming (Steimer, 2002; Ressler, 2010; Perusini and Fanselow, 2015). Researchers can also study these indicators during the social encounter itself (e.g., during the fear conditioning session) that leads to the acquisition and expression of a fear memory.

Another distinction arises in the types of classical conditioning that rodents undergo to acquire observational fear: contextual versus auditory-cued fear conditioning. Observational contextual fear conditioning consists of placing a demonstrator and observer into a context, separated by a clear divider. While in this context, the demonstrator gets shocked multiple times while the observer watches, without getting shocked themselves. The next day, the observer is placed back into the context in which the demonstrator was shocked and is assessed for fear expression. In observational auditory-cued fear conditioning, the demonstrator and observer are again placed in the context as described above. However, now an auditory tone is played before each shock is delivered to the demonstrator. The rodents therefore learn to associate the tone (conditioned stimulus [CS]) with the shock (unconditioned stimulus), in addition to contextual associations. The next day, the observer is placed in the demonstrator compartment and played the tones. Fear expression and learning are assessed in response to the tones, usually through increases in freezing. The rodent can also be placed in a new context to explicitly test the cue-shock association formed independent of context.

When determining the necessary factors involved in socially mediated fear learning, it is also important at the outset to distinguish rats and mice because of potential differences in social cognition and related behaviors (Ellenbroek and Youn, 2016). For instance, rats and mice differ with regards to the necessity of prior experience with unconditioned stimuli for an observer to acquire a fear association by observation of a conspecific (Chen et al., 2009; Bruchey et al., 2010; Jeon et al., 2010; E. J. Kim et al., 2010; Atsak et al., 2011; Pereira et al., 2012; Sanders et al., 2013; Allsop et al., 2018).

\section{Mice and observational fear conditioning}

In mice, there have been reports that an observer needs to have undergone fear conditioning themselves to acquire a long-term fear memory by observing a demonstrator (Sanders et al., 2013; Allsop et al., 2018). For example, using a contextual fear conditioning paradigm, Sanders et al. (2013) found that mice froze in response to a demonstrator being shocked only if the observer had previously experienced a direct shock themselves. Similarly, Allsop et al. (2018) used an auditory-cued fear-conditioning paradigm and found that, although both experienced and naive observers froze to the tones during the conditioning session, only experienced observers froze significantly more than baseline in response to the tone the next day when placed in the demonstrator compartment. The experimenters suggested that previous self-experience of fear conditioning was necessary for the subjects to learn and to freeze during recall in the auditory cued fear paradigm. They attributed this necessity to the fact that the threat of a shock is invisible and that experience with the shock is needed for the observer to associate the cues, context, and response of the conspecific with the similar shock experience.

In contrast, other studies using similar paradigms to induce observational contextual or auditory-cued fear conditioning demonstrated that mice not only froze during observational fear conditioning sessions but also acquired a long-term fear memory from a conspecific without direct prior experience of shocks themselves (Chen et al., 2009; Jeon et al., 2010). The salience of the social experience may explain these contradictory results. With observational auditory-cued learning, one study (Chen et al., 2009) found that, when an observer watched two demonstrators receiving shocks, prior experience was not required to induce freezing in the observer, as long as the observer was placed back into the training context for testing. In contrast, prior experience was necessary to induce freezing when only one demonstrator was present. This suggests that, when the social indication of threat is sufficiently potent and enough contextual information is present, mice can learn to react to a cue with fear. Similarly, in a study using contextual conditioning, observer rodents socially acquired fear without having prior exposure to a shock when the demonstrators received a strong and repetitive shock protocol (20 shocks at $1 \mathrm{~mA}$, lasting $2 \mathrm{~s}$, delivered every $10 \mathrm{~s}$ for $4 \mathrm{~min}$ ) (Jeon et al., 2010). In contrast, in a separate study in which demonstrators received 6 shocks at $0.7 \mathrm{~mA}$, lasting $1 \mathrm{~s}$, 
and delivered every $15 \mathrm{~s}$ for $\sim 3.5 \mathrm{~min}$, prior experience was necessary for observers to acquire fear (Sanders et al., 2013). It is important to note that the former study used a stronger protocol specifically because they did not observe homogeneous fear responses from either the demonstrators or observers when more standard fear conditioning protocols were attempted. Therefore, it seems that mice must experience a threshold in salience from the social experience both to freeze during the conditioning session and to acquire the fear memory for recall the subsequent day. Even with similar shock protocols, however, social learning paradigms can yield different results. A recent experiment (Nomura et al., 2019) used the same strong, repetitive shock protocol as Jeon et al. (2010), but they found that naive mice who observed a cage mate getting shocked in a context subsequently froze only a nonsignificant average of $8 \%$ of the time during recall (compared with mice that observed a nonshocked cage mate), whereas Jeon et al. (2010) found a significant freezing level of $25 \%$. Interestingly, the mice that had undergone direct fear conditioning in Nomura et al. (2019) froze at similar levels to mice that underwent observational fear conditioning in Jeon et al. (2010). Given that direct fear conditioning produces greater freezing during recall than observational fear conditioning (Morozov and Ito, 2018), it is possible that the mice in Nomura et al. (2019) had lower baseline freezing and anxiety levels, or did not learn as well, leading to overall low levels of fear behaviors. Another possibility for the discrepancy in freezing levels between the two studies is that Nomura et al. (2019) measured contextual freezing during a second reexposure to the context, whereas Jeon et al. (2010) measured freezing on the first reexposure. In this case, the first context exposure without shock in Nomura et al. (2019) may have acted as a brief extinction session.

In addition, it is important to note that more socially oriented mice (e.g., C57/BL6 compared with BALB) (Chen et al., 2009) may imbue a social encounter with more salience and thus show enhanced acquisition of fear from a conspecific. Whether the salience of the experience affects the size, firing rates, or plastic properties of neural ensembles recruited in these social engrams is largely unknown but may contribute to the variable effects seen in these studies.

\section{Rats, observational fear conditioning, and fear conditioning by proxy}

In contrast to mice, rats do not need prior direct fear conditioning experience to acquire or recall a social engram formed when observing a demonstrator rat undergo contextual or auditorycued fear conditioning (Yusufishaq and Rosenkranz, 2013; Twining et al., 2017). In addition, rats have been shown to undergo fear conditioning by proxy, a behaviorally distinct phenomenon in which a demonstrator rat that was previously conditioned is placed back in the conditioning context and represented with the fear-associated auditory cue in the presence of an observer rat. The fear response of the demonstrator as they recall the conditioning memory can subsequently induce a fear response in a naive observer rat during a long-term memory retrieval test (Bruchey et al., 2010; Jones et al., 2014; Jones and Monfils, 2016). To date and to our understanding, this has yet to be shown to occur in mice. Notably, prior experience of a shock appears to increase the amount of freezing behavior seen in the observer during conditioning via fear conditioning by proxy (E. J. Kim et al., 2010; Atsak et al., 2011; Pereira et al., 2012). As suggested by Jones (2015), however, the amount of freezing exhibited by the demonstrator as well as the observer during the conditioning session do not correlate with subsequent long-term memory retrieval of the socially acquired fear memory. Therefore, prior experience may influence freezing at the time of conditioning without necessarily affecting the strength of the observer's long-term social memory. One potential reason for this dichotomy is that the demonstrator and observer have direct contact with one another during the session. Previous studies have shown that physical contact is essential to elicit the underlying neuronal activity that coincides with fear transmission (Kiyokawa et al., 2019), and that the number of times the two conspecifics come in contact appears to be positively correlated with subsequent recall of the observer the next day (Bruchey et al., 2010; Jones et al., 2014; Jones, 2015; Jones and Monfils, 2016; Morozov and Ito, 2018). In order for there to be contact, though, the observer rat needs to investigate the demonstrator rat through movement, which can confound freezing levels, thus necessitating additional proxies for measuring fear outputs in general.

Given such differing paradigms across a variety of rodent models, it has been difficult to come to conclusive evidence about the circuitry necessary to elicit social transmission of fear. Cued and contextual fear conditioning recruit different neural mechanisms (Selden et al., 1991; LeDoux and Phillips, 1992; Rudy, 1993; Stanton, 2000), and therefore can yield a wide range of results contingent on which techniques are used, which brain regions are manipulated, and which behavioral outputs are measured. Notably, social learning is often reported to be much more variable and less robust than classical fear conditioning, adding to the complexity of each reported finding. This perhaps stems from the multitude of behavioral and mnemonic variables involved (Debiec and Olsson, 2017), making it ever more crucial to develop concrete and reproducible paradigms for these types of experiments to yield consistent results as we further investigate the phenomenon of social fear learning.

\section{Mechanisms of fear transmission}

Although still not completely understood, neural and behavioral mechanisms of observational fear conditioning have been extensively reviewed (Olsson and Phelps, 2007; Debiec and Olsson, 2017). However, many questions remain regarding the mechanisms underlying fear conditioning by proxy, especially because of its high variability in results and small effect sizes.

A key mechanism for fear conditioning by proxy is the emission of $22 \mathrm{kHz}$ ultrasonic vocalizations. Ultrasonic vocalization at this frequency are emitted by rats in fear or anxiety-like states across many tasks, including elevated plus maze, predator presentation, and fear conditioning (Blanchard et al., 1991; Jeon et al., 2010; Demaestri et al., 2019). Kim et al. (2010) elegantly showed that observer rats became conditioned to their own 22 $\mathrm{kHz}$ vocalizations during prior fear conditioning, and that this was necessary for the observers to obtain a social fear memory from a demonstrator emitting these vocalizations in a different fear conditioning experience (E. J. Kim et al., 2010). On the other hand, a more recent study demonstrated that many demonstrator animals induced freezing in the experienced observers even if they did not emit $22 \mathrm{kHz}$ vocalizations, indicating that these vocalizations were not necessary to transfer fear (Jones and Monfils, 2016). However, the authors of the latter study noted that those who did emit these vocalizations enhanced the transmission of the fear to the observer. This suggests that there is inherent variability across subjects in their capacity to socially acquire a fear engram. 
Another mechanism for fear conditioning by proxy is suggested by the fact that there is an association between physical touch and the amount of fear transfer in this paradigm. Recently, social neuroscience researchers have discovered a more ubiquitous role of the cortex in social fear transmission in humans and rodents than previously appreciated (Keum and Shin, 2016; Allsop et al., 2018; Ito and Morozov, 2019). Two regions closely associated with vicarious fear learning are the ACC and the insular cortex. The role of the insular cortex in vicarious fear learning in rodents has been relatively understudied, but it is a promising area that could help explain the ability of rodents to have "empathic" or socially driven fear learning, despite any differences in social cognition and its underlying neuroanatomy compared with humans and nonhuman primates. The insular cortex has dense connections with the amygdala and hippocampus (Ghaziri et al., 2018; Rogers-Carter et al., 2018), forming a neural circuit in which social relevance, empathy-like behaviors, and sensory information can integrate into a valenced memory engram. Hence, the insular cortex provides an intriguing neural substrate capable of achieving the somatosensory-emotional integration required for fear conditioning by proxy.

\section{Familiarity, sex, and empathy}

A common observation across studies regardless of species, strain, or observational learning paradigm is the enhancement of learning with increased familiarity or relatedness between subjects (Zentall and Levine, 1972; Carlier and Jamon, 2006; Saggerson and Honey, 2006; Burke et al., 2010; Bruchey et al., 2010; Jeon et al., 2010; Jeon and Shin, 2011; Yusufishaq and Rosenkranz, 2013; Jones et al., 2014; Debiec and Olsson, 2017; Pisansky et al., 2017; Allsop et al., 2018; Morozov, 2018; Sivaselvachandran et al., 2018; Nomura et al., 2019). In general, with increased familiarity or relatedness, there is both increased transfer of fear during observational fear learning sessions and enhanced fear memory recall by the observer the following day. Although untested, we propose that the social engram representing a familiar conspecific is likely playing a role in this phenomenon, possibly through reward prediction processes. We posit that, when a social engram is activated and recognition of a familiar conspecific occurs, there is an expectation for a rewarding experience (Okuyama, 2018; Modi and Sahin, 2019), an assumption discussed at the end of this section. When a conspecific is shocked or reacts negatively to an environmental stimulus, therefore, the error representation is greater for a familiar compared with an unfamiliar conspecific, leading to enhanced learning of fear from the familiar animal as a result of increased salience and negative valence.

In addition to reward prediction processes, the activity of a social engram could also function to promote an optimal brain state for encoding new information through observation. Engrams are constantly updated as dynamic representations of information in the brain, which in their active state induce enduring molecular, circuit, and systems-level changes (Tonegawa et al., 2015a, 2015b). For instance, when a memory transitions from dormancy to an active state, a cascade of molecular events ensue including the synthesis of proteins and induction of synaptic plasticity (Poo et al., 2016). In addition, the retrieval of engrams is thought to activate CREB, a known enhancer of memory consolidation (Hall et al., 2001) with complementary roles in modulating cellular excitability (Cai et al., 2016; Josselyn and Tonegawa, 2020). We speculate that, when a social engram is reactivated during an observational learning session, similar protein synthesis and LTP processes are active early on, leading to increased CREB and related proteins necessary for memory consolidation and updating (Tay et al., 2019). Consequently, observational fear learning is readily encoded as social information in the brain, likely now causally linked to the social memory of the conspecific. In fear learning, even if not directly harmed, the subjects now have a heightened affinity to encode frightening experiences per se, leading to an ability to acquire fear socially.

Interestingly, however, there may exist a sex difference in terms of the effects of familiarity on fear learning. Indeed, females learn fear observationally from both familiar and nonfamiliar conspecifics (Jones et al., 2014; Pisansky et al., 2017), whereas males seem to have enhanced fear acquisition from a familiar conspecific (Pisansky et al., 2017). Although additional work needs to be done to investigate this phenomenon, it closely parallels sex differences seen in human social interaction (Dumais and Veenema, 2016) and learning (Schulte-Rüther et al., 2008; Christov-Moore et al., 2014; Hidalgo et al., 2019) and could provide a model for investigating mechanisms underlying such sex-dependent behavioral outcomes in observational fear conditioning.

Sex differences in social fear learning likely stem from differences in neuronal activity, physiology, and receptor density in multiple brain regions. Sex differences in oxytocin signaling might be particularly important. Oxytocin is a neuropeptide that has been implicated in a variety of social behaviors (Fineberg and Ross, 2017 ; Dudek et al., 2016; A. S. Smith et al., 2016; Meira et al., 2018; Sivaselvachandran et al., 2018), including maternal and pup interactions (Pedersen et al., 1992; Fineberg and Ross, 2017 ; Mitre et al., 2016), as well as learning (Engelmann et al., 1996; Heinrichs et al., 2004; Gur et al., 2014; Sarnyai and Kovács, 2014), including social fear learning (Rogers-Carter et al., 2018; Keum and Shin, 2019). A contribution of oxytocin to sex differences in social fear learning is suggested by experiments showing that administration of oxytocin to male mice increases social fear learning from unfamiliar conspecific to levels achieved with familiar mice; as noted above, this phenomenon is seen in females without additional oxytocin administration (Pisansky et al., 2017). Furthermore, recent work has demonstrated sex differences in oxytocin receptor distribution across the brain, including parts of the hippocampus, amygdala, and PFC (Mitre et al., 2016). Notably, females have a much greater density of oxytocin receptors in CA2 than males (Mitre et al., 2016), a region that, as discussed above, has unique functions in social behavior (Dudek et al., 2016; A. S. Smith et al., 2016; Meira et al., 2018; Modi and Sahin, 2019; Oliva et al., 2020). Thus, CA2 oxytocin levels might contribute to enhanced social fear potentiation and expression in social situations.

Another factor that might contribute to sex differences in observational fear learning is differences in the vocalizations emitted between conspecifics. For example, female mice emit higher frequency calls at a higher rate during conditioning sessions than mice male do (Pisansky et al., 2017). These differences may again point to a role for oxytocin because male and female mice have different distributions of oxytocin receptors in sensory cortices, including the auditory cortex and olfactory bulb (Mitre et al., 2016). In addition, the role of sex differences within mPFC regions and their projections to brain areas required for fear conditioning (e.g., the amygdala) are ripe for future investigation (Markham and Juraska, 2002; Lebron-Milad et al., 2012; Rilling et al., 2014; Dumais and Veenema, 2016; Allsop et al., 2018). Specifically, the ACC and insular cortex, which are associated with vicarious fear learning (Tanimizu et al., 2017) and vocalization (Bennett et al., 2019), should be further studied in the 
context of ultrasonic vocalization-mediated sex differences in observational fear learning.

Sex differences in the formation of social memories may be modulated by levels of familiarity between subjects and how they experience a given social interaction. In theory, interactions with familiar conspecifics can be considered rewarding, as they can drive behaviors, such as conditioned place preference rather than avoidance (Trezza et al., 2011; Lee and Beery, 2019) and often recruit neural circuits associated with reward (Trezza et al., 2011; Caldwell and Albers, 2016). However, rodents in group settings also have negative interactions that may bias a social engram and its effects on learning, which underscores the complexity of social behaviors and the emotions they may recruit in a subject (van der Kooij and Sandi, 2012; Lee and Beery, 2019; Varholick et al., 2019). For example, dominance hierarchies are formed through aggression and competition, especially in male rodents (Beatty, 1979). A social memory is an amalgamation of prior experiences with conspecifics (van der Kooij and Sandi, 2012), and therefore will vary in valence depending on these experiences. Sex, as well as group/kin, differences in aggression and affiliation are potential behavioral factors affecting all social learning described in this review. It should be noted, however, that sex differences in processing and learning from conspecific fear are not always observed (Han et al., 2020).

\section{Bidirectionality of social and Pavlovian learning}

There is a bidirectional link between social fear learning and classical fear learning in that either experience can prime the other. For example, a prior fear conditioning experience will enhance subsequent observational fear learning in a new context or to a new cue (Sanders et al., 2013; Allsop et al., 2018). In addition, an observer who has experienced a conspecific undergoing fear conditioning will show enhanced acquisition of subsequent, directly experienced fear conditioning (Nomura et al., 2019). Another study showed that the observer did not even have to be present during the fear conditioning session of the demonstrator to prime later direct fear learning (Knapska et al., 2010). Knapska et al. (2010) exposed observer rats to recently fear-conditioned conspecifics and then later fear-conditioned the observers themselves. Having this social interaction without actually seeing the demonstrator get shocked increased both acquisition of the observer's own fear memory and performance in a shock-motivated shuttle avoidance task. Although the specific mechanisms involved in these phenomena are still relatively unknown, a recent study has elucidated potential involvement of the dorsal hippocampus (Nomura et al., 2019). Nomura et al. (2019) used a doxycycline activity-dependent system to visualize and compare the neural ensembles active during observational fear conditioning with those active during a subsequent self-experienced fear conditioning session. As expected, those who experienced observational fear conditioning had greater freezing during recall of the self-experienced fear conditioning. Interestingly, the CA1 cells active during the observational fear conditioning and direct conditioning significantly overlapped, but this was not the case in CA3. This suggests that prior observational fear conditioning primes discrete hippocampal engrams for later learning, enhancing the effect of direct fear conditioning. In addition, the finding that CA3 did not have many overlapping cells suggests a pathway for priming other than the Schaffer collateral pathway. Such priming might be mediated by CA2, which has direct and dense projections to CA1 and relatively few to CA3.

Another potential mechanism that could be at play in socially mediated priming of fear learning is the formation of silent synapses between key areas, such as the PFC and amygdala during observational fear learning (Ito et al., 2015; Ito and Morozov, 2019). Recent studies have examined the role of dorsomedial PFC-amygdala silent synapses formed during observational fear conditioning in subsequent inhibitory avoidance learning. These studies suggest that silent synapses formed during observational fear conditioning are unsilenced during inhibitory avoidance learning (passive avoidance), facilitating LTP and learning in the task (Ito and Morozov, 2019). Knapska et al. (2010) reported similar priming effects when observer rats interacted with a recently fear-conditioned demonstrator in subsequent learning of a shock-motivated shuttle-avoidance task. In addition, they found that this social interaction significantly activated the basolateral amygdala, again pointing to its potential role in priming future direct learning by an observer (Knapska et al., 2006, 2010). Although different from direct contextual or tone fear conditioning, the passive and active avoidance tasks recruit partially overlapping brain structures, including the PFC (Gilmartin et al., 2014; Rozeske et al., 2015; Campese et al., 2016) and amygdala (J. J. Kim and Jung, 2006; F. Ramirez et al., 2015), suggesting that a similar mechanism might be responsible for enhanced conditioned freezing responses after social observation of distress. Which and how these circuits (whether overlapping or not) are recruited in different fear-related tasks (J. J. Kim and Jung, 2006) offers another fruitful avenue for future research investigating the social modulation of synaptic plasticity.

\section{Social buffering of learning and memory}

Social interactions during fearful experiences have two competing roles in fear expression. On one hand, as described above, is the enhancing effect of social interactions on self-experienced fear. On the other hand, social interactions can serve as a buffer for fear. The dual effects of social interaction on fear conditioning are present from the preconditioning stage to retrieval and extinction, with modulatory effects of familiarity. This suggests that the social engram can influence each stage of learning and memory of nonsocial experiences.

\section{Preconditioning social buffering}

In one of the first demonstrations of the buffering effects of a social interaction before fear conditioning (Guzmán et al., 2009), naive mice were placed in a context with a nonfearful demonstrator for 2 separate days. On the third day, the naive mice were fear-conditioned in the same context, and fear memory recall was tested the following day. Interestingly, mice exposed to nonfearful demonstrators showed less freezing during recall than controls not pre-exposed to a demonstrator, whereas exposure to a fearful demonstrator itself did not enhance the freezing response during recall. The placement of a subject in a previously associated social context during fear conditioning therefore acts as a counteragent against a fear memory trace, lowering the fear response during recall, but not completely abolishing it. In addition, the buffering that occurred before fear conditioning was modality-dependent: context, and not auditory cue-induced fear conditioning, was affected by the nonfearful conspecific's presence.

As emphasized earlier, the strength of fear conditioning and the type of social learning can influence the mechanisms of transmission and offer insight into the neural circuitry involved in any resulting dissociation. For social buffering, the competition between social and fear traces formed in a given context can modulate each other. For example, stronger fear conditioning eliminates the buffering effects of social interactions and leads to a dominant fear representation and response. Conversely, weaker 


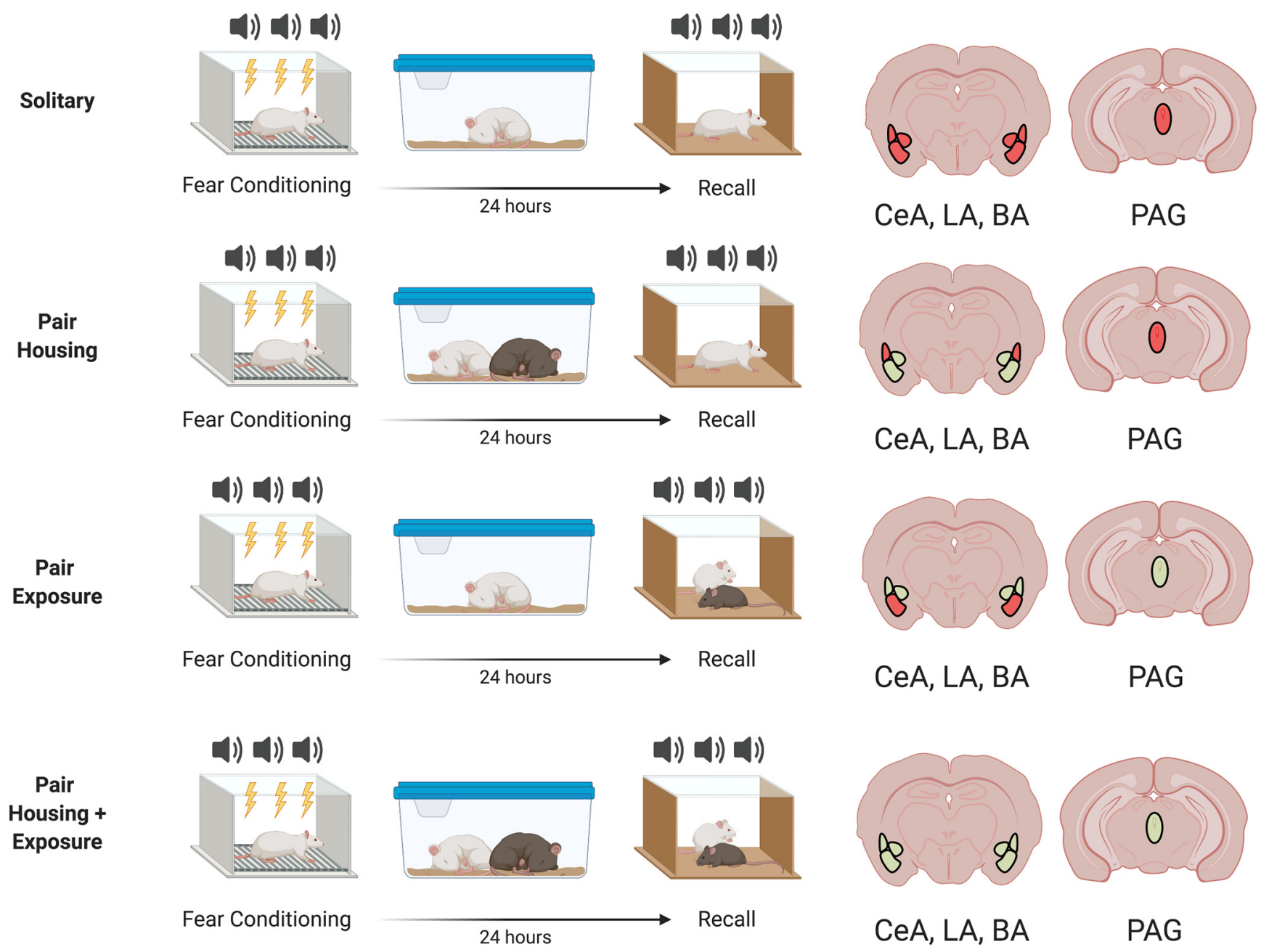

Figure 4. Two types of social buffering. In all paradigms, a rodent is fear-conditioned to auditory cues alone and then tested for recall $24 \mathrm{~h}$ later (see Kiyokawa et al., 2007). Recall in the solitary condition induces significant activation of CeA, LA, BA, and PAG, as indicated by red on the schematics of brain sections in the figure. Recall is also accompanied by activity in the HPA axis, SIH, and freezing behavior. In pair-housing, the rodent is housed with a conspecific for the $24 \mathrm{~h}$ between conditioning and recall. In this group, there is significant activation of the LA and PAG, but not of the BA and CeA. Although freezing behavior is still observed, there is reduced HPA activation and SIH. In pair exposure, the conditioned rodent is housed overnight in isolation but placed with a conspecific during recall. In this case, there is significant BA activation, and reduced HPA axis, CeA, and LA activity than when animals are housed and tested without conspecifics present. Freezing behavior is abolished in this condition, but SIH remains high. When a conspecific is present overnight as well as during testing, activation is reduced in all the aforementioned fear-associated regions, as well as a significant decrease in HPA axis activation, SIH, and freezing behavior.

fear conditioning may lead to a dominant buffering response, significantly reducing freezing behavior to floor levels. When considering the underlying neural mechanisms of prefear conditioning social buffering, brain-region specificity and necessity can also be investigated across different paradigms. For example, cued fear conditioning does not always require an intact hippocampus (Hornik et al., 1987; Gerull and Rapee, 2002; Jeon et al., 2010; E. J. Kim et al., 2010). Contextual fear conditioning, on the other hand, is heavily reliant on the hippocampus for acquisition and recall of the recent experience. Therefore, since social buffering before fear conditioning only shows context-specific effects (Guzmán et al., 2014), it suggests that the hippocampus plays a crucial role in such a phenomenon by allowing the integration of spatial information with the significance of a social encounter into a joint representation of a socially relevant environment.

\section{Post-fear conditioning and recall buffering}

Social buffering can also occur in rodents between acquiring a fear memory and recalling the memory the following day. In one study, rats were fear-conditioned to auditory cues and tested for recall to the conditioned cues in a new context $24 \mathrm{~h}$ later
(Kiyokawa et al., 2007). In this study, the rats showed increased freezing to the conditioned cue and stress-induced hyperthermia (SIH) and HPA axis activation (measured by paraventricular nucleus [PVN] activity), as well as elevated activity in the infralimbic cortex (IL), central amygdala (CeA), lateral amygdala (LA), basal amygdala (BA), and periaqueductal gray (PAG). The authors then tested two potential social buffering paradigms: housing the rat with another conspecific between fear conditioning and recall (pair-housing), or placing a conspecific with the fear-conditioned rat during the recall session (pair exposure) (Fig. 4).

When a fear-conditioned rat was pair-housed with an unfamiliar conspecific after fear conditioning, IL, CeA, and BA activation were significantly lowered, and activation of the HPA axis was attenuated, as were autonomic fear responses (i.e., $\mathrm{SIH}$ ) to the CS during recall the next day (Kiyokawa et al., 2007). Nevertheless, freezing behavior, LA, and ventrolateral PAG activity remained high during tone presentation. In contrast, when a conspecific was placed with a fear-conditioned animal during the recall session but not during housing overnight, there was a decrease in behavioral response by the conditioned rat (decreased freezing), as well as decreased HPA axis, CeA, LA, and PAG 
activity. However, stress induced hyperthermia, IL, and BA activation remained high.

As evidenced in the above-mentioned results, dissociations are often found between behavioral responses to fear, such as freezing, and physiological responses, such as SIH (Yang et al., 2011; Machida et al., 2019). SIH is associated with the activation of the autonomic nervous system and anxiety-related states. Body temperature increases in rodents in response to many types of stressors, including restraint, exposure to novel environments, and expectation of an aversive event (e.g., auditory-cued fear conditioning) (Groenink et al., 1994; Zethof et al., 1995; Kikusui et al., 2001). Fittingly, SIH has been considered a candidate for quantitative measurement of anxiety-like states in animals. However, fear and anxiety are highly interconnected, and both factors are involved in fear memory acquisition, retrieval, and generalization (Indovina et al., 2011; Dunsmoor and Paz, 2015; Zhang et al., 2019). Therefore, measuring more homeostatic and regulatory functions, such as body temperature, could point us to understudied mechanistic measures of neural and time-dependent variables in fear conditioning affected by pair-housing.

What could explain the divergent effects of the two social buffering conditions described above? One possibility is that hippocampus-mediated contextual generalization is sensitive to paired-housed social buffering. This would thereby influence which downstream neural circuits are activated during fear recall. To that end, in one study a ventral hippocampus to CeA pathway was shown to mediate context-dependent retrieval of cued fear memories but not contextual fear retrieval alone (Xu et al., 2016). Therefore, if solitary rats have a generalized fear memory that includes both contextual and cued elements, then we predict that contextual generalization in the new context would lead to increased activity in the hippocampus, CeA, and BA (Rozeske et al., 2015; Asok et al., 2018). Perhaps pair-housing decreases contextual generalization, leading to decreases in BA and CeA activity, as well as a downregulation of SIH responses, without affecting the auditory-cue fear response, which would coincide with increased freezing to CS as well as LA and ventrolateral PAG activity.

Contextual generalization immediately following fear conditioning can be beneficial for a rodent's survival by increasing detection of potential threats and adaptively modulating homeostatic functions (Asok et al., 2018). For instance, after fear conditioning, a typical physiological response is a decrease in the quality of REM sleep, whether measured by theta power, bout frequency, or bout duration (Sanford et al., 2001; Hellman and Abel 2007; Madan et al., 2008; Macone et al., 2011; Yang et al., 2011). This REM sleep disturbance is hypothesized to be because of increased arousal and release of corticosterone after a frightening experience, therefore increasing wakefulness and the individual's ability to detect subsequent danger (Tang et al., 2005). Because REM quality is critical for hippocampal contextual consolidation, it is plausible that pair-housing had anxiolytic effects that prevented reductions in REM sleep after fear conditioning (Hellman and Abel 2007; Madan et al., 2008; Macone et al., 2011; Yang et al., 2011). This could, in turn, increase contextual specificity leading to less generalization during recall in the new context (Hagewoud et al., 2011). Notably, Kodama et al. (2011) performed a study following up on the social buffering results of Kiyokawa et al. (2007) and found that pair-housing only affected SIH if done for at least $12 \mathrm{~h}$ between fear conditioning and recall. Pair-housing for $6 \mathrm{~h}$ after fear conditioning, or $6 \mathrm{~h}$ before recall, had no buffering effect. Given that the time window of the effect coincides with a rodent's light cycle (Friedman and Walker, 1968; Tang et al., 2005;
Wellman et al., 2008), this again suggests that sleep alterations may play an essential role in pair-housed social buffering.

Another possible explanation for the above-mentioned findings is that pair-housing inhibits the consolidation, instead of decreasing generalization, of a contextual engram after fear conditioning. Accordingly, a contextual consolidation impairment would lead to a lack of generalization because of the absence of a robust fear engram with which to begin. The ventral hippocampus to CeA pathway would therefore be inactive during fear recall in the pairhoused animals, decreasing SIH response (though perhaps without affecting an auditory cue fear response that is contingent on separate pathways). In the pair-exposure paradigm, in contrast, rats were not pair-housed overnight. Consequently, we propose that fear-conditioned animals with identical consolidation processes as controls and continued to generalize across contexts the next day, which might explain the increase in SIH. While we propose this ventral hippocampus-CeA pathway is recruited depending on the paradigm used, it is highly possible that alternative pathways associated with heterogeneous CeA activity, especially when one considers its genetically defined inputs and outputs (J. Kim et al., 2017) related to reward and fear learning, could also contribute to modulating behavioral and physiological fear responses.

Another study elucidated the underlying mechanisms for the other effects of pair exposure, including the decrease in freezing and suppression of cue-induced physiological responses. They found that the presence of a conspecific during recall led to the inhibition of the LA through an indirect mediation of the lateral intercalated cell (ITC) mass of the amygdala (a GABAergic cluster of cells surrounding the amygdala) by the anterior olfactory peduncle (Minami et al., 2019). We propose that pair exposure may activate the IL and BA, which are known regions associated with decreased fear behavior in rodents Bloodgood et al., 2018) and were shown to be elevated in the study by Kiyokawa et al. (2007). These brain regions subsequently further inhibit LA and CeA activation, leading to a decrease in behavioral response (freezing) and HPA axis activation.

Kiyokawa et al. (2007) also tested the intersectional effects of both pair-housing after fear conditioning and pair exposure during recall. They found an additive effect of buffering, in which behavioral, HPA, and SIH fear responses were abolished. Continuing with our proposition, in this instance, there would not be any context generalization because the pair-housing leads to either more specific contextual consolidation or no contextual consolidation, and no fear responses during recall, and the pair exposure inhibits LA, CeA, and other fear response nuclei (PVN, PAG, etc.).

\section{Extinction buffering}

Social buffering can also affect the formation of an extinction engram, as suggested by Mikami et al. $(2020,2016)$. For these studies, $24 \mathrm{~h}$ after auditory-cued fear conditioning, animals were returned to the conditioning chamber, either with an unfamiliar conspecific or alone, and were presented with 24 CS tones for extinction training. The next day, they were tested for extinction recall alone. Rats paired with a conspecific during extinction training froze significantly less to the CS during extinction recall, and they also had reduced HPA response and LA activation. These effects were mediated by a decrease in corticosterone release during extinction training in the presence of a conspecific, leading to enhanced within-session extinction (Mikami et al., 2020). Notably, memory recall was suppressed only when the CS was replayed in the same context as extinction training, suggesting that context, rather than auditory cues per se, is associated with extinction enhancement (i.e., reduced freezing responses) via social buffering. 
A

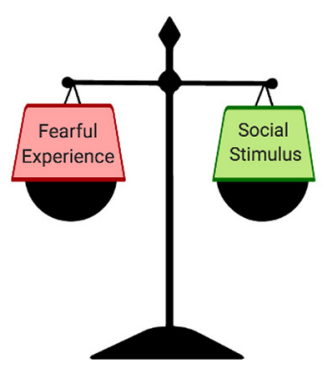

B

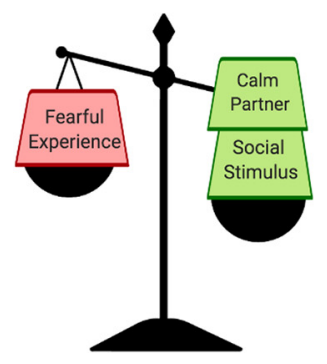

C
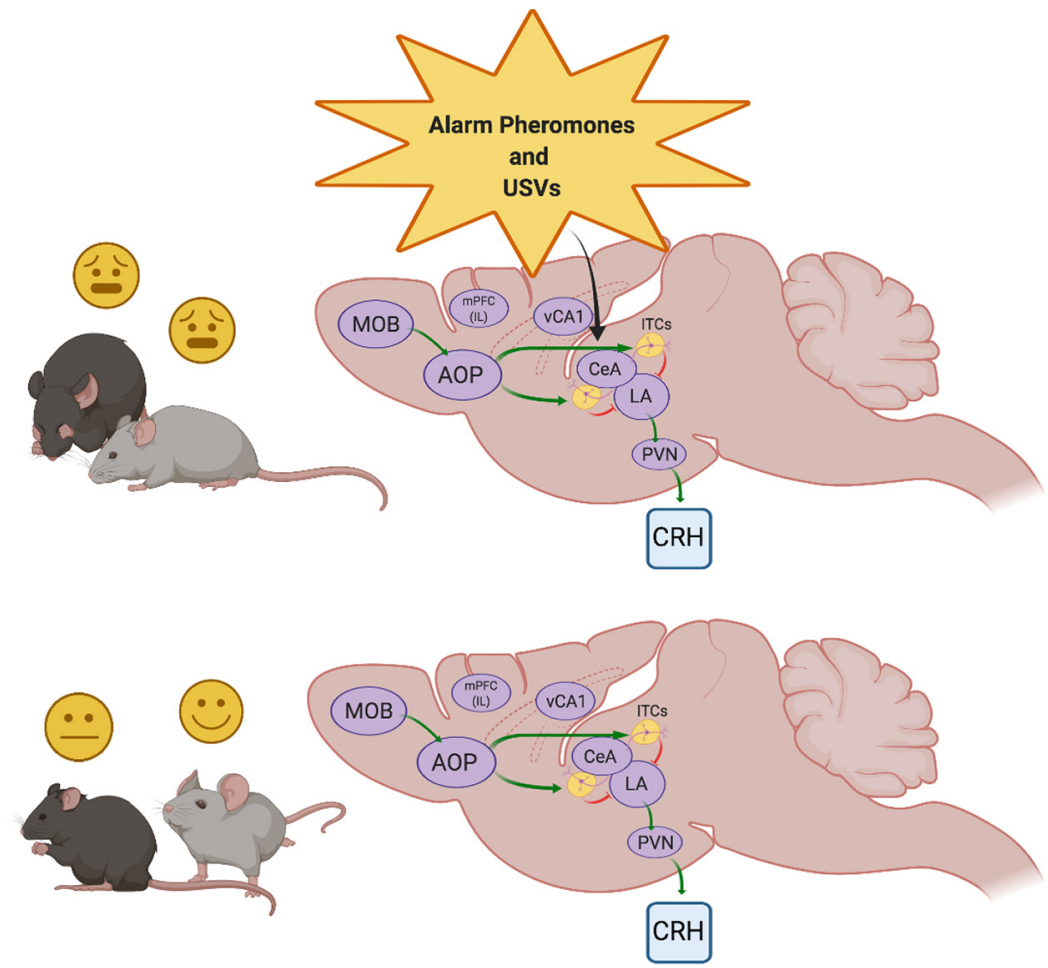

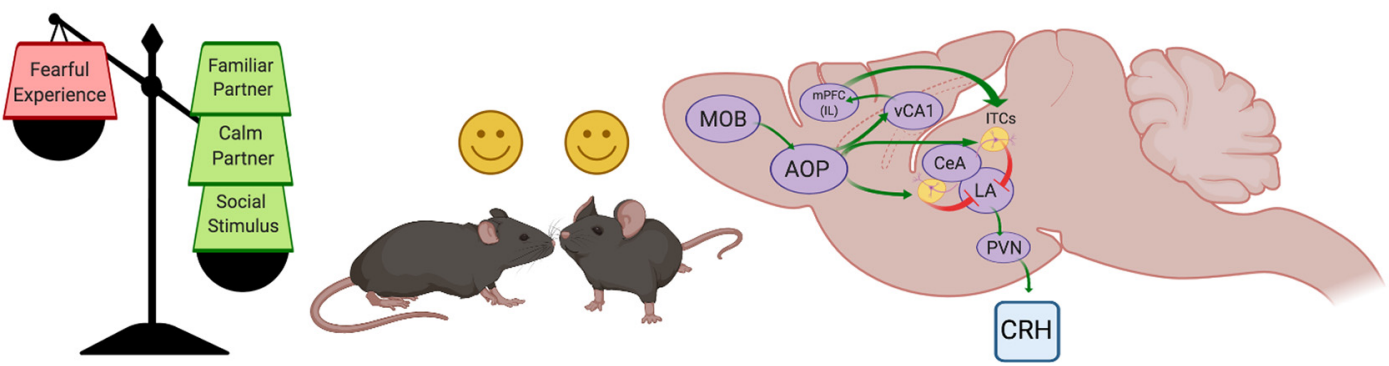

Figure 5. Proposed neural mechanisms of social buffering. During recall of a negative memory in rodents, fear is classically quantified as increases in freezing, which can be buffered with the presence of a conspecific $(\boldsymbol{A}-\boldsymbol{C})$. When placed back into the fear conditioning context with a conspecific, this shifts the scales of pro-fear (red weights) and reduced fear (green weights) toward the side of a mitigated fear response. The neural mechanisms are still unclear, but they include putative "buffering" olfactory information traveling from the medial olfactory bulb (MOB) to the anterior olfactory peduncle (AOP). This activation leads to excitation (depicted as green arrows) of the bundles of GABAergic neurons (ITCs) scattered around the amygdala. The excitation of the ITCs leads to inhibition (depicted as red blunted arrows) of the CeA and LA, leading to a decreased activation of the HPA axis (PVN activation) and corticotropin-releasing hormone (CRH) secretion. If the unfamiliar conspecific was also previously fear-conditioned and is therefore anxious in the chamber, the alarm pheromones and ultrasonic vocalizations elicited by the conspecific work against the buffering $(\boldsymbol{A})$, leading to a less robust attention of freezing compared with a conspecific that is has not been fear-conditioned in the chamber with the subject $(\boldsymbol{B})$. If the conspecific is nonfearful and familiar, the classical social-buffering neural circuit still applies. but the olfactory information of a familiar conspecific also travels from the MOB to the AOP, which activates the "social engram" in ventral CA1 (C). This activates the IL cortex of the MPFC, which is known to control fear responses by activating ITCs. The added excitation of the ITCs leads to an increased inhibition of the amygdala fear response and subsequent attenuation of the HPA axis response.

This also implicates the hippocampus in extinction enhancement via social buffering, which relies on corticosterone to modulate fear memory (Pugh et al., 1997). If and how the hippocampus is involved have not yet been described but are a promising next step in our understanding of social buffering.

\section{The social engram, familiarity, and buffering}

All of the social buffering studies discussed above have used unfamiliar rodents as conspecifics. However, similar to social learning of fear, there is an effect of familiarity in social buffering as well. A recent study compared the social buffering effects of a familiar versus unfamiliar conspecific's odor presented during fear recall and found a larger decrease in freezing, LA activation, and PVN activation when the odor was from familiar conspecifics than when it was from an unfamiliar conspecific, but both odors had social buffering effects relative to control, isolated animals (Kiyokawa et al., 2014). We propose that the social engram in vCA1 may play a role in the enhanced effect with familiar conspecifics, given its various outputs to areas, including the PFC and amygdala. More specifically, odor of the conspecific is associated with the social engram of the familiar conspecific, which activates the IL cortex of the PFC (Spehr et al., 2006; Lungwitz et al., 2014; Levy et al., 2019; Gutzeit et al., 2020). The IL cortex, a major region for inhibition of fear expression, has direct projections to the ITCs of the amygdala (Amano et al., 2010; Ciocchi et al., 2010). Therefore, the IL may send excitatory signals to the GABAergic cells of the amygdala, inhibiting fear behavior-inducing areas, such as the CeA. The inhibition observed in the parallel neural pathway for social buffering with an unfamiliar conspecific (Amano et al., 2010; Ciocchi et al., 2010) compounds this effect, leading to a greater social buffering for familiar conspecifics 
(Fig. 5). This is supported by a recent optogenetic study, in which IL cells active during a social interaction with a familiar conspecific were stimulated during recall of fear conditioning: this stimulation attenuated fear behaviors compared with controls (Gutzeit et al., 2020). This suggests separable neural pathways mediate fear buffering by familiar versus unfamiliar conspecifics because the PFC has specific anxiolytic properties dependent on familiarity itself (Lungwitz et al., 2014). Together, these findings suggest a contribution of the social engram in social buffering, a concept that can be explored as it may have implications in our understanding of both rodent and human social cognition.

\section{Conclusion and future directions}

This review focused on the social modulation of learning and memory, with an emphasis on the component roles of the hippocampus and social engrams. As this is an emerging field of neuroscience, much more work needs to be done to fully understand the principles and neural mechanisms underlying the complexities of social behavior. We suggest that researchers continue to standardize the procedures between laboratories and through time to measure the variability of social interactions and their effects between subjects. The species of study, paradigms, and sex differences are all intertwined and most likely affect each other. Because of the complexity of social behavior, the results can be variable and heterogeneous, making it all the more important to keep the paradigms and manipulations consistent.

The role of the hippocampus in social modulation of learning and memory, especially with the burgeoning research in CA2, is a field wide open for discovery. How does CA2 causally modulate social behaviors? What parts of the hippocampus are conserved for social behavior in rodents, and what can that tell us about their capacity for higher-order social cognition?

The discovery of the "social engram" and empathic responses in rodents may mean that there is a level of social intelligence that can acknowledge and assess other conspecifics in a way that may enable higher-order cognition in an even more complex and nuanced manner than once previously thought. With these new discoveries, researchers have not only made previously elusive social behavior and cognition visible and measurable, but also have allowed it to be manipulated in ways that may provide insight into these questions and lead to therapeutic interventions in the future.

\section{References}

Agee LA, Monfils MH (2018) Effect of demonstrator reliability and recency of last demonstration on acquisition of a socially transmitted food preference. R Soc Open Sci 5:172391.

Allsop SA, Wichmann R, Mills F, Burgos-Robles A, Chang CJ, Felix-Ortiz AC, Vienne A, Beyeler A, Izadmehr EM, Glober G, Cum MI, Stergiadou J, Anandalingam KK, Farris K, Namburi P, Leppla CA, Weddington JC, Nieh EH, Smith AC, Ba D, et al. (2018) Corticoamygdala transfer of socially derived information gates observational learning. Cell 173:13291342.e18.

Amano T, Unal CT, Paré D (2010) Synaptic correlates of fear extinction in the amygdala. Nat Neurosci 13:489-494.

Asok A, Kandel ER, Rayman JB (2018) The neurobiology of fear generalization. Front Behav Neurosci 12:329.

Atsak P, Orre M, Bakker P, Cerliani L, Roozendaal B, Gazzola V, Moita M, Keysers C (2011) Experience modulates vicarious freezing in rats: a model for empathy. PLoS One 6:e21855.

Bandura A, Ross D, Ross SA (1961) Transmission of aggression through imitation of aggressive models. J Abnorm Soc Psychol 63:575-582.
Beatty WW (1979) Gonadal hormones and sex differences in nonreproductive behaviors in rodents: organizational and activational influences. Horm Behav 12:112-163.

Bennett PJ, Maier E, Brecht M (2019) Involvement of rat posterior prelimbic and cingulate area 2 in vocalization control. Eur J Neurosci 50:31643180.

Benoy A, Dasgupta A, Sajikumar S (2018) Hippocampal area CA2: an emerging modulatory gateway in the hippocampal circuit. Exp Brain Res 236:919-931.

Biggio F, Gorini G, Utzeri C, Olla P, Marrosu F, Mocchetti I, Follesa P (2009) Chronic vagus nerve stimulation induces neuronal plasticity in the rat hippocampus. Int J Neuropsychopharmacol 12:1209-1221.

Blanchard RJ, Blanchard DC, Agullana R, Weiss SM (1991) Twenty-two kHz alarm cries to presentation of a predator, by laboratory rats living in visible burrow systems. Physiol Behav 50:967-972.

Bloodgood DW, Sugam JA, Holmes A, Kash TL (2018) Fear extinction requires infralimbic cortex projections to the basolateral amygdala. Transl Psychiatry 8:60.

Bruchey AK, Jones CE, Monfils MH (2010) Fear conditioning by-proxy: social transmission of fear during memory retrieval. Behav Brain Res 214:80-84.

Bunsey M, Eichenbaum H (1995) Selective damage to the hippocampal region blocks long-term retention of a natural and nonspatial stimulusstimulus association. Hippocampus 5:546-556.

Burke CJ, Tobler PN, Baddeley M, Schultz W (2010) Neural mechanisms of observational learning. Proc Natl Acad Sci USA 107:14431-14436.

Burton S, Murphy D, Qureshi U, Sutton P, O'Keefe J (2000) Combined lesions of hippocampus and subiculum do not produce deficits in a nonspatial social olfactory memory task. J Neurosci 20:5468-5475.

Buzsáki G, Moser EI (2013) Memory, navigation and theta rhythm in the hippocampal-entorhinal system. Nat Neurosci 16:130-138.

Cai DJ, Aharoni D, Shuman T, Shobe J, Biane J, Song W, Wei B, Veshkini M, La-Vu M, Lou J, Flores SE, Kim I, Sano Y, Zhou M, Baumgaertel K, Lavi A, Kamata M, Tuszynski M, Mayford M, Golshani P, et al. (2016) A shared neural ensemble links distinct contextual memories encoded close in time. Nature 534:115-118.

Caldwell HK, Albers HE (2016) Oxytocin, vasopressin, and the motivational forces that drive social behaviors. In: Behavioral neuroscience of motivation (SimpsonEH, Balsam PD, eds), pp 51-103. New York: Springer.

Calvo-Ochoa E, Hernández-Ortega K (2014) Short-term high-fat-and-fructose feeding produces insulin signaling alterations accompanied by neurite and synaptic reduction and astroglial activation in the rat. J Cereb Blood Flow Metab 34:1001-1008.

Campese VD, Sears RM, Moscarello JM, Diaz-Mataix L, Cain CK, LeDoux JE (2016) The neural foundations of reaction and action in aversive motivation. Curr Top Behav Neurosci 27:171-195.

Carballo-Márquez A, Vale-Martínez A, Guillazo-Blanch G, Martí-Nicolovius M (2009) Muscarinic receptor blockade in ventral hippocampus and prelimbic cortex impairs memory for socially transmitted food preference. Hippocampus 19:446-455.

Carcea I, Froemke RC (2019) Biological mechanisms for observational learning. Curr Opin Neurobiol 54:178-185.

Carlier P, Jamon M (2006) Observational learning in C57BL/6j mice. Behav Brain Res 174:125-131.

Carlini VP, Varas MM, Cragnolini AB, Schiöth HB, Scimonelli TN, de Barioglio SR (2004) Differential role of the hippocampus, amygdala, and dorsal raphe nucleus in regulating feeding, memory, and anxiety-like behavioral responses to ghrelin. Biochem Biophys Res Commun 313:635-641.

Castle M, Comoli E, Loewy AD (2005) Autonomic brainstem nuclei are linked to the hippocampus. Neuroscience 134:657-669.

Charuvastra A, Cloitre M (2008) Social bonds and posttraumatic stress disorder. Annu Rev Psychol 59:301-328.

Chen QL, Panksepp JB, Lahvis GP (2009) Empathy is moderated by genetic background in mice. PLoS One 4:e4387.

Chevaleyre V, Piskorowski RA (2016) Hippocampal area CA2: an overlooked but promising therapeutic target. Trends Mol Med 22:645-655.

Chiang MC, Huang AJ, Wintzer ME, Ohshima T, McHugh TJ (2018) A role for CA3 in social recognition memory. Behav Brain Res 354:22-30.

Choleris E, Kavaliers M (1999) Social learning in animals: sex differences and neurobiological analysis. Pharmacol Biochem Behav 64:767-776. 
Christov-Moore L, Simpson EA, Coudé G, Grigaityte K, Iacoboni M, Ferrari PF (2014) Empathy: gender effects in brain and behavior. Neurosci Biobehav Rev 46:604-627.

Ciocchi S, Herry C, Grenier F, Wolff SB, Letzkus JJ, Vlachos I, Ehrlich I, Sprengel R, Deisseroth K, Stadler MB, Müller C, Lüthi A (2010) Encoding of conditioned fear in central amygdala inhibitory circuits. Nature 468:277-282.

Clifton PG, Vickers SP, Somerville EM (1998) Little and often: ingestive behavior patterns following hippocampal lesions in rats. Behav Neurosci 112:502-511.

Conte R, Paolucci M (2001) Intelligent Social learning. Journal of Artificial Societies and Social Simulation vol. 4 , no. 1.

Countryman RA, Gold PE (2007) Rapid forgetting of social transmission of food preferences in aged rats: relationship to hippocampal CREB activation. Learn Mem 14:350-358.

Countryman RA, Kaban NL, Colombo PJ (2005) Hippocampal c-Fos is necessary for long-term memory of a socially transmitted food preference. Neurobiol Learn Mem 84:175-183.

Danjo T, Toyoizumi T, Fujisawa S (2018) Spatial representations of self and other in the hippocampus. Science 359:213-218.

Darmohray DM, Jacobs JR, Marques HG, Carey MR (2019) Spatial and temporal locomotor learning in mouse cerebellum. Neuron 102:217-231.e4.

Davidson TL, Jarrard LE (1993) A role for hippocampus in the utilization of hunger signals. Behav Neural Biol 59:167-171.

Debiec J, Olsson A (2017) Social fear learning: from animal models to human function. Trends Cogn Sci 21:546-555.

Demaestri C, Brenhouse HC, Honeycutt JA (2019) $22 \mathrm{kHz}$ and $55 \mathrm{kHz}$ ultrasonic vocalizations differentially influence neural and behavioral outcomes: implications for modeling anxiety via auditory stimuli in the rat. Behav Brain Res 360:134-145.

Denny CA, Lebois E, Ramirez S (2017) From engrams to pathologies of the brain. Front Neural Circuits 11:1-20.

DeVito LM, Konigsberg R, Lykken C, Sauvage M, Young WS, Eichenbaum H (2009) Vasopressin $1 \mathrm{~b}$ receptor knock-out impairs memory for temporal order. J Neurosci 29:2676-2683.

Dhar M, Wayman GA, Zhu M, Lambert TJ, Davare MA, Appleyard SM (2014) Leptin-induced spine formation requires TrpC channels and the CaM kinase cascade in the hippocampus. J Neurosci 34:10022-10033.

D’Mello AM, Stoodley CJ (2015) Cerebro-cerebellar circuits in autism spectrum disorder. Front Neurosci 9:408.

Dragoi G, Tonegawa S (2013) Distinct preplay of multiple novel spatial experiences in the rat. Proc Natl Acad Sci USA 110:9100-9105.

Dudek SM, Alexander GM, Farris S (2016) Rediscovering area CA2: unique properties and functions. Nat Rev Neurosci 17:89-102.

Dumais KM, Veenema AH (2016) Vasopressin and oxytocin receptor systems in the brain: sex differences and sex-specific regulation of social behavior. Front Neuroendocrinol 40:1-23.

Dunsmoor JE, Paz R (2015) Fear generalization and anxiety: behavioral and neural mechanisms. Biol Psychiatry 78:336-343.

Dziura SL, Thompson JC (2019) The neural representational space of social memory. Open Mind 3:1-12.

Eichenbaum H (2004) Hippocampus: cognitive processes and neural representations that underlie declarative memory. Neuron 44:109-120.

Eichenbaum H (2014) Time cells in the hippocampus: a new dimension for mapping memories. Nat Rev Neurosci 15:732-744.

Eichenbaum H (2015) The hippocampus as a cognitive map ... of social space. Neuron 87:9-11

Ellenbroek B, Youn J (2016) Rodent models in neuroscience research: is it a rat race? Dis Model Mech 9:1079-1087.

Engelmann M, Wotjak CT, Neumann I, Ludwig M, Landgraf R (1996) Behavioral consequences of intracerebral vasopressin and oxytocin: focus on learning and memory. Neurosci Biobehav Rev 20:341-358.

Ferbinteanu J (2019) Memory systems 2018: towards a new paradigm. Neurobiol Learn Mem 157:61-78.

Fernández M, Mollinedo-Gajate I, Peñagarikano O (2018) Neural circuits for social cognition: implications for autism. Neuroscience 370:148-162.

Fernandez-Lamo I, Gomez-Dominguez D, Sanchez-Aguilera A, Oliva A, Morales AV, Valero M, Cid E, Berenyi A, Menendez de la Prida L (2019) Proximodistal organization of the CA2 hippocampal area. Cell Rep 26:1734-1746.e6.

Fineberg SK, Ross DA (2017) Oxytocin and the Social Brain. Biol Psychiatry 81:e19-e21.
Flaherty CF, Coppotelli C, Hsu D, Otto T (1998) Excitotoxic lesions of the hippocampus disrupt runway but not consummatory contrast. Behav Brain Res 93:1-9.

Flinn MV, Nepomnaschy PA, Muehlenbein MP, Ponzi D (2011) Evolutionary functions of early social modulation of hypothalamic-pituitary-adrenal axis development in humans. Neurosci Biobehav Rev 35:1611-1629.

Friedman AH, Walker CA (1968) Circadian rhythms in rat mid-brain and caudate nucleus biogenic amine levels. J Physiol 197:77-85.

Galef BG Jr, Stein M (1985) Demonstrator influence on observer diet preference: analyses of critical social interactions and olfactory signals. Anim Learn Behav 13:31-31.

Galef BG Jr, Wigmore SW (1983) Transfer of information concerning distant foods: a laboratory investigation of the 'information-centre' hypothesis. Anim Behav 31:748-758.

Galef BG Jr, Mason JR, Preti G, Bean NJ (1988) Carbon disulfide: a semiochemical mediating socially induced diet choice in rats. Physiol Behav 42:119-124

Gariépy JF, Watson KK, Du E, Xie DL, Erb J, Amasino D, Platt ML (2014) Social learning in humans and other animals. Front Neurosci 8:58.

Gerull FC, Rapee RM (2002) Mother knows best: effects of maternal modelling on the acquisition of fear and avoidance behaviour in toddlers. Behav Res Ther 40:279-287.

Ghaziri J, Tucholka A, Girard G, Boucher O, Houde JC, Descoteaux M, Obaid S, Gilbert G, Rouleau I, Nguyen DK (2018) Subcortical structural connectivity of insular subregions. Sci Rep 8:1-12.

Gilmartin MR, Balderston NL, Helmstetter FJ (2014) Prefrontal cortical regulation of fear learning. Trends Neurosci 37:455-464.

Grillo CA, Piroli GG, Hendry RM, Reagan LP (2009) Insulin-stimulated translocation of GLUT4 to the plasma membrane in rat hippocampus is PI3-kinase dependent. Brain Res 1296:35-45.

Groenink L, van der Gugten J, Zethof T, van der Heyden J, Olivier B (1994) Stress-induced hyperthermia in mice: hormonal correlates. Physiol Behav 56:747-749.

Gur R, Tendler A, Wagner S (2014) Long-term social recognition memory is mediated by oxytocin-dependent synaptic plasticity in the medial amygdala. Biol Psychiatry 76:377-386.

Gutzeit VA, Ahuna K, Santos TL, Cunningham AM, Sadsad Rooney M, Denny CA, Donaldson ZR (2020) Optogenetic reactivation of prefrontal social neural ensembles mimics social buffering of fear. Neuropsychopharmacology, 45:1068-1077.

Guzmán YF, Tronson NC, Guedea A, Huh KH, Gao C, Radulovic J (2009) Social modeling of conditioned fear in mice by non-fearful conspecifics. Behav Brain Res 201:173-178

Guzmán YF, Tronson NC, Sato K, Mesic I, Guedea AL, Nishimori K, Radulovic J (2014) Role of oxytocin receptors in modulation of fear by social memory. Psychopharmacology (Berl) 231:2097-2105.

Hagewoud R, Bultsma LJ, Barf RP, Koolhaas JM, Meerlo P (2011) Sleep deprivation impairs contextual fear conditioning and attenuates subsequent behavioural, endocrine and neuronal responses. J Sleep Res 20:259-266.

Hall J, Thomas KL, Everitt BJ (2001) Fear memory retrieval induces CREB phosphorylation and Fos expression within the amygdala. Eur J Neurosci 13:1453-1458.

Han Y, Sichterman B, Carrillo M, Gazzola V, Keysers C (2020) Similar levels of emotional contagion in male and female rats. Sci Rep 10:1-12.

Heinrichs M, Meinlschmidt G, Wippich W, Ehlert U, Hellhammer DH (2004) Selective amnesic effects of oxytocin on human memory. Physiol Behav 83:31-38.

Hellman K, Abel T (2007) Fear conditioning increases NREM sleep. Behav Neurosci 121:310-323.

Hidalgo V, Pulopulos MM, Salvador A (2019) Acute psychosocial stress effects on memory performance: relevance of age and sex. Neurobiol Learn Mem 157:48-60.

Hornik R, Risenhoover N, Gunnar M (1987) The effects of maternal positive, neutral, and negative affective communications on infant responses to new toys. Child Dev 58:937-944.

Hsu TM, Hahn JD, Konanur VR, Noble EE, Suarez AN, Thai J, Nakamoto EM, Kanoski SE (2015) Hippocampus ghrelin signaling mediates appetite through lateral hypothalamic orexin pathways. eLife 4:e11190.

Hsu TM, Noble EE, Reiner DJ, Liu CM, Suarez AN, Konanur VR, Hayes MR, Kanoski SE (2018a) Hippocampus ghrelin receptor signaling 
promotes socially mediated learned food preference. Neuropharmacology 131:487-496.

Hsu TM, Noble EE, Liu CM, Cortella AM, Konanur VR, Suarez AN, Reiner DJ, Hahn JD, Hayes MR, Kanoski SE (2018b) A hippocampus to prefrontal cortex neural pathway inhibits food motivation through glucagon-like peptide-1 signaling. Mol Psychiatry 23:1555-1565.

Indovina I, Robbins TW, Núñez-Elizalde AO, Dunn BD, Bishop SJ (2011) Fear-conditioning mechanisms associated with trait vulnerability to anxiety in humans. Neuron 69:563-571.

Ito W, Erisir A, Morozov A (2015) Observation of distressed conspecific as a model of emotional trauma generates silent synapses in the prefrontalamygdala pathway and enhances fear learning, but ketamine abolishes those effects. Neuropsychopharmacology 40:2536-2545.

Ito W, Morozov A (2019) Prefrontal-amygdala plasticity enabled by observational fear. Neuropsychopharmacology 44:1778-1787.

Jarrard LE (1973) The hippocampus and motivation. Psychol Bull 79:1-12.

Jeon D, Shin HS (2011) A mouse model for observational fear learning and the empathetic response. Curr Protoc Neurosci 8:27.

Jeon D, Kim S, Chetana M, Jo D, Ruley HE, Rabah D, Kinet JP, Shin HS (2010) Observational fear learning involves affective pain system. Nat Neurosci 13:482-488.

Jones CE (2015) The social transmission of associative fear in rats: mechanisms and applications of fear conditioning by proxy. $\mathrm{PhD}$ thesis. University of Texas at Austin.

Jones CE, Monfils MH (2016) Dominance status predicts social fear transmission in laboratory rats. Anim Cogn 19:1051-1069.

Jones CE, Riha PD, Gore AC, Monfils MH (2014) Social transmission of Pavlovian fear: fear-conditioning by-proxy in related female rats. Anim Cogn 17:827-834.

Josselyn SA, Tonegawa S (2020) Memory engrams: recalling the past and imagining the future. Science 367:eaaw4325.

Kajiwara R, Wouterlood FG, Sah A, Boekel AJ, Baks-Te Bulte LT, Witter MP (2008) Convergence of entorhinal and CA3 inputs onto pyramidal neurons and interneurons in hippocampal area CA1: an anatomical study in the rat. Hippocampus 18:266-280.

Kesner RP, Lee I, Gilbert P (2004) A behavioral assessment of hippocampal function based on a subregional analysis. Rev Neurosci 15:333-351.

Keum S, Shin HS (2016) Rodent models for studying empathy. Neurobiol Learn Mem 135:22-26.

Keum S, Shin HS (2019) Neural basis of observational fear learning: a potential model of affective empathy. Neuron 104:78-86.

Kikusui T, Takigami S, Takeuchi Y, Mori Y (2001) Alarm pheromone enhances stress-induced hyperthermia in rats. Physiol Behav 72:45-50.

Kim EJ, Kim ES, Covey E, Kim JJ (2010) Social transmission of fear in rats: the role of 22-kHz ultrasonic distress vocalization. PLoS One 5:e15077.

Kim JJ, Jung MW (2006) Neural circuits and mechanisms involved in Pavlovian fear conditioning: a critical review. Neurosci Biobehav Rev 30:188-202.

Kim J, Zhang X, Muralidhar S, LeBlanc SA, Tonegawa S (2017) Basolateral to central amygdala neural circuits for appetitive behaviors. Neuron 93:1464-1479.e5.

Kiyokawa Y, Hennessy MB (2018) Comparative studies of social buffering: a consideration of approaches, terminology, and pitfalls. Neurosci Biobehav Rev 86:131-141.

Kiyokawa Y, Takeuchi Y, Mori Y (2007) Two types of social buffering differentially mitigate conditioned fear responses. Eur J Neurosci 26:36063613.

Kiyokawa Y, Wakabayashi Y, Takeuchi Y, Mori Y (2012) The neural pathway underlying social buffering of conditioned fear responses in male rats. Eur J Neurosci 36:3429-3437.

Kiyokawa Y, Honda A, Takeuchi Y, Mori Y (2014) A familiar conspecific is more effective than an unfamiliar conspecific for social buffering of conditioned fear responses in male rats. Behav Brain Res 267:189-193.

Kiyokawa Y, Li Y, Takeuchi Y (2019) A dyad shows mutual changes during social buffering of conditioned fear responses in male rats. Behav Brain Res 366:45-55.

Knapska E, Nikolaev E, Boguszewski P, Walasek G, Blaszczyk J, Kaczmarek L, Werka T (2006) Between-subject transfer of emotional information evokes specific pattern of amygdala activation. Proc Natl Acad Sci USA 103:3858-3862.

Knapska E, Mikosz M, Werka T, Maren S (2010) Social modulation of learning in rats. Learn Mem 17:824-831.
Kodama Y, Kiyokawa Y, Takeuchi Y, Mori Y (2011) Twelve hours is sufficient for social buffering of conditioned hyperthermia. Physiol Behav 102:188-192.

Kohn B (1976) Observation and discrimination learning in the rat: Effects of stimulus substitution. Learning and Motivation 7:303-312.

Lacey EA, Solomon NG (2003) Social biology of rodents: trends, challenges, and future directions. J Mammal 84:1135-1140.

Langston RF, Stevenson CH, Wilson CL, Saunders I, Wood ER (2010) The role of hippocampal subregions in memory for stimulus associations. Behav Brain Res 215:275-291.

Lebron-Milad K, Abbs B, Milad MR, Linnman C, Rougemount-Bücking A, Zeidan MA, Holt DJ, Goldstein JM (2012) Sex differences in the neurobiology of fear conditioning and extinction: a preliminary fMRI study of shared sex differences with stress-arousal circuitry. Biol Mood Anxiety Disord 2:1.

LeDoux JE, Phillips RG (1992) Differential contribution of amygdala and hippocampus to cued and contextual fear conditioning. Behav Neurosci 106:274-285.

Lee NS, Beery AK (2019) Neural circuits underlying rodent sociality: a comparative approach. In: Neuroendocrine regulation of behavior (Coolen LM, Grattan DR, eds), pp 211-238. New York: Springer.

Leggio MG, Molinari M, Neri P, Graziano A, Mandolesi L, Petrosini L (2000) Representation of actions in rats: the role of cerebellum in learning spatial performances by observation. Proc Natl Acad Sci USA 97:2320-2325.

Levy DR, Tamir T, Kaufman M, Parabucki A, Weissbrod A, Schneidman E, Yizhar O (2019) Dynamics of social representation in the mouse prefrontal cortex. Nat Neurosci 22:2013-2022.

Lungwitz EA, Stuber GD, Johnson PL, Dietrich AD, Schartz N, Hanrahan B, Shekhar A, Truitt WA (2014) The role of the medial prefrontal cortex in regulating social familiarity-induced anxiolysis. Neuropsychopharmacology 39:1009-1019.

Maccaferri G (2011) Modulation of hippocampal stratum lacunosum-moleculare microcircuits. J Physiol 589:1885-1891.

Machida M, Sutton AM, Williams BL, Wellman LL, Sanford LD (2019) Differential behavioral, stress, and sleep responses in mice with different delays of fear extinction. Sleep 42:zsz147.

Macone BW, O'Malley M, Datta S (2011) Sharing stressful experiences attenuates anxiety-related cognitive and sleep impairments. Behav Brain Res 222:351-356.

Madan V, Brennan FX, Mann GL, Horbal AA, Dunn GA, Ross RJ, Morrison AR (2008) Long-term effect of cued fear conditioning on REM sleep microarchitecture in rats. Sleep 31:497-503.

Maren S, Luan Phan K, Liberzon I (2013) The contextual brain: implications for fear conditioning, extinction and psychopathology. Nat Rev Neurosci $14: 417-428$.

Markham JA, Juraska JM (2002) Aging and sex influence the anatomy of the rat anterior cingulate cortex. Neurobiol Aging 23:579-588.

Matochik JA (1988) Role of the main olfactory system in recognition between individual spiny mice. Physiol Behav 42:217-222.

Meira T, Leroy F, Buss EW, Oliva A, Park J, Siegelbaum SA (2018) A hippocampal circuit linking dorsal CA2 to ventral CA1 critical for social memory dynamics. Nat Commun 9:1-14.

Mikami K, Kiyokawa Y, Takeuchi Y, Mori Y (2016) Social buffering enhances extinction of conditioned fear responses in male rats. Physiol Behav 163:123-128.

Mikami K, Kiyokawa Y, Ishii A, Takeuchi Y (2020) Social buffering enhances extinction of conditioned fear responses by reducing corticosterone levels in male rats. Horm Behav 118:104654.

Minami S, Kiyokawa Y, Takeuchi Y (2019) The lateral intercalated cell mass of the amygdala is activated during social buffering of conditioned fear responses in male rats. Behav Brain Res 372:112065.

Mitre M, Marlin BJ, Schiavo JK, Morina E, Norden SE, Hackett TA, Aoki CJ, Chao MV, Froemke RC (2016) A distributed network for social cognition enriched for oxytocin receptors. J Neurosci 36:2517-2535.

Mkrtchian A, Roiser JP, Robinson OJ (2017) Threat of shock and aversive inhibition: induced anxiety modulates Pavlovian-instrumental interactions. J Exp Psychol Gen 146:1694-1704.

Modi ME, Sahin M (2019) A unified circuit for social behavior. Neurobiol Learn Mem 165:106920.

Monfils MH, Agee LA (2019) Insights from social transmission of information in rodents. Genes Brain Behav 18:e12534. 
Montagrin A, Saiote C, Schiller D (2018) The social hippocampus. Hippocampus 28:672-679.

Morozov A (2018) Behavioral modulation by social experiences in rodent models. Curr Protoc Neurosci 84:1-14.

Morozov A, Ito W (2018) Social modulation of fear: facilitation vs buffering. Genes Brain Behav 18:1-8.

Mou X, Ji D (2016) Social observation enhances cross-environment activation of hippocampal place cell patterns. eLife 5:1-26.

Nomura H, Teshirogi C, Nakayama D, Minami M, Ikegaya Y (2019) Prior observation of fear learning enhances subsequent self-experienced fear learning with an overlapping neuronal ensemble in the dorsal hippocampus. Mol Brain 12:1-8.

O'Keefe J, Nadel L (1978) The hippocampus as a cognitive map. Oxford: Clarendon.

Okuyama T (2018) Social memory engram in the hippocampus. Neurosci Res 129:17-23.

Okuyama T, Kitamura T, Roy DS, Itohara S, Tonegawa S (2016) Ventral CA1 neurons store social memory. Science 353:1536-1544.

Oliva A, Fernández-Ruiz A, Leroy F, Siegelbaum SA (2020) Hippocampal CA2 ripples recruit social replay and promote social memory. Nature. Advance online publication. Retrieved March 05, 2020. DOI: 10.1101/ 2020.03.03.975599.

Olsson A, Phelps EA (2007) Social learning of fear. Nat Neurosci 10:10951102.

Pedersen CA, Caldwell JD, Peterson G, Walker CH, Mason GA (1992) Oxytocin activation of maternal behavior in the rat. Curr Biol 652:58-69.

Pereira AG, Cruz A, Lima SQ, Moita MA (2012) Silence resulting from the cessation of movement signals danger. Curr Biol 22:R627-R28.

Perusini JN, Fanselow MS (2015) Neurobehavioral perspectives on the distinction between fear and anxiety. Learn Mem 22:417-425.

Petrosini L, Molinari M, Dell'Anna ME (1996) Cerebellar contribution to spatial event processing: Morris Water Maze and T-Maze. Eur J Neurosci 8:1882-1896.

Pisansky MT, Hanson LR, Gottesman II, Gewirtz JC (2017) Oxytocin enhances observational fear in mice. Nat Commun 8:1-11.

Poo MM, Pignatelli M, Ryan TJ, Tonegawa S, Bonhoeffer T, Martin KC, Rudenko A, Tsai LH, Tsien RW, Fishell G, Mullins C, Gonçalves JT, Shtrahman M, Johnston ST, Gage FH, Dan Y, Long J, Buzsáki G, Stevens C (2016) What is memory? The present state of the engram. BMC Biol 14:40.

Pugh CR, Tremblay D, Fleshner M, Rudy JW (1997) A selective role for corticosterone in contextual-fear conditioning. Behav Neurosci 111:503-511.

Ramirez F, Moscarello JM, LeDoux JE, Sears RM (2015) Active avoidance requires a serial basal amygdala to nucleus accumbens shell circuit. J Neurosci 35:3470-3477.

Ramirez S, Liu X, MacDonald CJ, Moffa A, Zhou J, Redondo RL, Tonegawa S (2015) Activating positive memory engrams suppresses depression-like behaviour. Nature 522:335-339.

Ressler KJ (2010) Amygdala activity, fear, and anxiety: modulation by stress. Biol Psychiatry 67:1117-1119.

Rilling JK, DeMarco AC, Hackett PD, Chen X, Gautam P, Stair S, Haroon E, Thompson R, Ditzen B, Patel R, Pagnoni G (2014) Sex differences in the neural and behavioral response to intranasal oxytocin and vasopressin during human social interaction. Psychoneuroendocrinology 39:237-248.

Robinson DL, Heien ML, Wightman RM (2002) Frequency of dopamine concentration transients increases in dorsal and ventral striatum of male rats during introduction of conspecifics. J Neurosci 22:10477-10486.

Rogers-Carter MM, Varela JA, Gribbons KB, Pierce AF, McGoey MT, Ritchey M, Christianson JP (2018) Insular cortex mediates approach and avoidance responses to social affective stimuli. Nat Neurosci 21:404-414.

Ross RS, McGaughy J, Eichenbaum H (2005) Acetylcholine in the orbitofrontal cortex is necessary for the acquisition of a socially transmitted food preference. Learn Mem 12:302-306.

Rozeske RR, Valerio S, Chaudun F, Herry C (2015) Prefrontal neuronal circuits of contextual fear conditioning. Genes Brain Behav 14:22-36.

Rudy JW (1993) Contextual conditioning and auditory cue conditioning dissociate during development. Behav Neurosci 107:887-891.

Saggerson AL, Honey RC (2006) Observational learning of instrumental discriminations in the rat: the role of demonstrator type. Q J Exp Psychol (Hove) 59:1909-1920.

Sanders J, Mayford M, Jeste D (2013) Empathic fear responses in mice are triggered by recognition of a shared experience. PLoS One 8:e74609.
Sanford LD, Silvestri AJ, Ross RJ, Morrison AR (2001) Influence of fear conditioning on elicited ponto-geniculo-occipital waves and rapid eye movement sleep. Arch Ital Biol 139:169-183.

Sarnyai Z, Kovács GL (2014) Oxytocin in learning and addiction: from early discoveries to the present. Pharmacol Biochem Behav 119:3-9.

Schacter DL, Eich JE, Tulving E (1978) Richard Semon's theory of memory. J Verbal Learn Verbal Behav 17:721-743.

Schafer M, Schiller D (2018) Navigating social space. Neuron 100:476-489.

Schiller D, Eichenbaum H, Buffalo EA, Davachi L, Foster DJ, Leutgeb S, Ranganath C (2015) Memory and space: towards an understanding of the cognitive map. J Neurosci 35:13904-13911.

Schmelzeis MC, Mittleman G (1996) The hippocampus and reward: effects of hippocampal lesions on progressive-ratio responding. Behav Neurosci 110:1049-1066.

Schulte-Rüther M, Markowitsch HJ, Shah NJ, Fink GR, Piefke M (2008) Gender differences in brain networks supporting empathy. Neuroimage 42:393-403.

Selden NR, Everitt BJ, Jarrard LE, Robbins TW (1991) Complementary roles for the amygdala and hippocampus in aversive conditioning to explicit and contextual cues. Neuroscience 42:335-350.

Shughrue PJ, Merchenthaler I (2000) Evidence for novel estrogen binding sites in the rat hippocampus. Neuroscience 99:605-612.

Sivaselvachandran S, Acland EL, Abdallah S, Martin LJ (2018) Behavioral and mechanistic insight into rodent empathy. Neurosci Biobehav Rev 91:130-137.

Smith AS, Williams Avram SK, Cymerblit-Sabba A, Song J, Young WS (2016) Targeted activation of the hippocampal CA2 area strongly enhances social memory. Mol Psychiatry 21:1137-1144.

Smith CA, Countryman RA, Sahuque LL, Colombo PJ (2007) Time-courses of Fos expression in rat hippocampus and neocortex following acquisition and recall of a socially transmitted food preference. Neurobiol Learn Mem 88:65-74

Sokolov AA (2018) The Cerebellum in Social Cognition. Front. Cell. Neurosci 12:145.

Spehr M, Kelliher KR, Li XH, Boehm T, Leinders-Zufall T, Zufall F (2006) Essential role of the main olfactory system in social recognition of major histocompatibility complex peptide ligands. J Neurosci 26:1961-1970.

Stanton ME (2000) Multiple memory systems, development and conditioning. Behav Brain Res 110:25-37.

Steimer T (2002) The biology of fear- and anxiety-related behaviors. Dialogues Clin Neurosci 4:231-249.

Storm EE, Tecott LH (2005) Social circuits: peptidergic regulation of mammalian social behavior. Neuron 47:483-486.

Suarez AN, Noble EE, Kanoski SE (2019) Regulation of memory function by feeding-relevant biological systems: following the breadcrumbs to the hippocampus. Front Mol Neurosci 12:101.

Takano Y, Ukezono M, Nakashima SF, Takahashi N, Hironaka N (2017) Learning of efficient behaviour in spatial exploration through observation of behaviour of conspecific in laboratory rats. R Soc Open Sci 4:170121.

Tang X, Yang L, Sanford LD (2005) Rat strain differences in freezing and sleep alterations associated with contextual fear. Sleep 28:1235-1244.

Tanimizu T, Kenney JW, Okano E, Kadoma K, Frankland PW, Kida S (2017) Functional connectivity of multiple brain regions required for the consolidation of social recognition memory. J Neurosci 37:4103-4116.

Tay KR, Flavell CR, Cassini L, Wimber M, Lee JL (2019) Postretrieval relearning strengthens hippocampal memories via destabilization and reconsolidation. J Neurosci 39:1109-1118.

Teyler TJ, Discenna P (1984) The topological anatomy of the hippocampus: a clue to its function. Brain Res Bull 12:711-719.

Thapa R, Sparks FT, Hanif W, Gulbrandsen T, Sutherland RJ (2014) Recent memory for socially transmitted food preferences in rats does not depend on the hippocampus. Neurobiol Learn Mem 114:113-116.

Tonegawa S, Liu X, Ramirez S, Redondo R (2015a) Memory engram cells have come of age. Neuron 87:918-931.

Tonegawa S, Pignatelli M, Roy DS, Ryan TJ (2015b) Memory engram storage and retrieval. Curr Opin Neurobiol 35:101-109.

Torregrossa MM, Taylor JR (2013) Learning to forget: manipulating extinction and reconsolidation processes to treat addiction. Psychopharmacology (Berl) 226:659-672.

Tracy AL, Jarrard LE, Davidson TL (2001) The hippocampus and motivation revisited: appetite and activity. Behav Brain Res 127:13-23. 
Trezza V, Campolongo P, Vanderschuren LJ (2011) Evaluating the rewarding nature of social interactions in laboratory animals. Dev Cogn Neurosci 1:444-458

Twining RC, Vantrease JE, Love S, Padival M, Rosenkranz JA (2017) An intra-amygdala circuit specifically regulates social fear learning. Nat Neurosci 20:459-469.

Tzakis N, Holahan MR (2019) Social memory and the role of the hippocampal CA2 region. Front Behav Neurosci 13:1-15.

Vale-Martínez A, Baxter MG, Eichenbaum H (2002) Selective lesions of basal forebrain cholinergic neurons produce anterograde and retrograde deficits in a social transmission of food preference task in rats: cholinergic basal forebrain and social memory. Eur J Neurosci 16:983-998.

van der Kooij MA, Sandi C (2012) Social memories in rodents: methods, mechanisms and modulation by stress. Neurosci Biobehav Rev 36:17631772.

Varholick JA, Pontiggia A, Murphy E, Daniele V, Palme R, Voelkl B, Würbel $\mathrm{H}$, Bailoo JD (2019) Social dominance hierarchy type and rank contribute to phenotypic variation within cages of laboratory mice. Sci Rep 9:13650.

Wang Y, Fontanini A, Katz DB (2006) Temporary basolateral amygdala lesions disrupt acquisition of socially transmitted food preferences in rats. Learn Mem 13:794-800.

Wellman LL, Yang L, Tang X, Sanford LD (2008) Contextual fear extinction ameliorates sleep disturbances found following fear conditioning in rats. Sleep 31:1035-1042.

Winocur G (1990) Anterograde and retrograde amnesia in rats with dorsal hippocampal or dorsomedial thalamic lesions. Behav Brain Res 38:145154
Winocur G, Moscovitch M (1999) Anterograde and retrograde amnesia after lesions to frontal cortex in rats. J Neurosci 19:9611-9617.

Winocur G, McDonald RM, Moscovitch M (2001) Anterograde and retrograde amnesia in rats with large hippocampal lesions. Hippocampus $11: 18-26$.

Wolff JO (2007) Social biology of rodents. Integr Zool 2:193-204.

Xu C, Krabbe S, Gründemann J, Botta P, Fadok JP, Osakada F, Saur D, Grewe BF, Schnitzer MJ, Callaway EM, Lüthi A (2016) Distinct hippocampal pathways mediate dissociable roles of context in memory retrieval. Cell 167:961-972.

Yang L, Wellman LL, Ambrozewicz MA, Sanford LD (2011) Effects of stressor predictability and controllability on sleep, temperature, and fear behavior in mice. Sleep 34:759-771.

Yusufishaq S, Rosenkranz JA (2013) Post-weaning social isolation impairs observational fear conditioning. Behav Brain Res 242:142-149.

Zentall TR (2006) Imitation: definitions, evidence, and mechanisms. Anim Cogn 9:335-353.

Zentall TR, Galef BG Jr (1988) Social learning: psychological and biological perspectives. Milton Park, UK: Taylor and Francis.

Zentall TR, Levine JM (1972) Observational learning and social facilitation in the rat. Science 178:1220-1222.

Zethof TJ, Van der Heyden JA, Tolboom JT, Olivier B (1995) Stress-induced hyperthermia as a putative anxiety model. Eur J Pharmacol 294:125-135.

Zhang YK, Ouyang TV, Lipina H, Wang Q Zhou (2019) Conditioned stimulus presentations alter anxiety level in fear-conditioned mice. Mol Brain $12: 28$. 